\title{
Practical Coupled Resonators in Domino Arrangements for Power Transmission and Distribution: Replacing Step-Down Power Transformers and Their Branches across the Power Grid
}

\author{
Athanasios G. Lazaropoulos \\ School of Electrical and Computer Engineering, National Technical University of Athens, 9 Iroon Polytechniou Street, \\ Zografou, 15780 Athens, Greece \\ Correspondence should be addressed to Athanasios G. Lazaropoulos; aglazaropoulos@gmail.com
}

Received 11 January 2013; Revised 2 May 2013; Accepted 7 June 2013

Academic Editor: Kamaruzzaman Sopian

Copyright (C) 2013 Athanasios G. Lazaropoulos. This is an open access article distributed under the Creative Commons Attribution License, which permits unrestricted use, distribution, and reproduction in any medium, provided the original work is properly cited.

\begin{abstract}
This paper considers the potential of replacing step-down power transformers of the entire power grid as well as part of their transmission line branches with wireless power transfer (WPT) technology components. Exploiting the state-of-the-art evolutions in the fields of WPT technology, coupled resonators in domino arrangements-domino coupled resonator (DCR) configurationsare proposed as suitable technological substitute for step-down power transformers and are investigated in terms of performance metrics such as power transfer efficiency (PTE) and transformation ratio (TR). The contribution of this paper is fivefold. First, an analytical theoretical analysis appropriate to the study of practical DCR configurations is demonstrated. In order to support the DCR configuration replacement venture, a detailed set of assumptions regarding efficient mid- and long-range high-power WPTs as well as related technical issues is first presented. The validity of the theoretical analysis is verified through experimental measurements. Second, applying the proposed theoretical analysis, a wealth of system parameters that mainly influences the PTE and TR of DCR configurations is identified. Their quantitative effect as well as corresponding DCR configuration adjustments are first presented. Third, an approximate method, denoted as approximate chain scattering matrix (CSM) method, is first introduced. Based on the scattering matrix theory formalism, the approximate CSM method is suitable for mid- and long-range DCR configurations when the theoretical analysis becomes computationally slow. The numerical results of approximate CSM method are compared with the respective ones of theoretical analysis validating the extent and the accuracy of approximate CSM method. Fourth, the potential of power transformer replacement with practical DCR configurations is thoroughly investigated in terms of their TRs. A plethora of high-voltage/medium-voltage (HV/MV), MV/low-voltage (MV/LV), and HV/LV power transformers used across the world is investigated verifying their replacement potential with practical DCR configurations in all the cases examined. Fifth, based on a detailed collection of dimensions concerning power transformers and transmission line branches, it is first verified that practical DCR configurations cannot only substitute all step-down power transformers of the today's power grid but also replace entire transmission line branches too. Finally, it is obvious that there is a long journey ahead for WPT technology and its ultramodern DCR configurations to be affordably, widely, reliably, sustainably, and safely adopted in the human society. During these first steps of WPT development for power transmission and distribution, theoretical analyses and visions are necessary. The last cable problem, that is, the seamless power delivery as easily as information is now transmitted through the air, is one of the major technological challenges of the 21st century, and, thus, WPT technology will certainly play key role.
\end{abstract}

\section{Introduction}

The fundamentals of wireless power transfer (WPT) have been discovered in the works of M. Faraday, H. C. Ørsted, and N. Tesla in the 19th and 20th centuries. WPT technology describes the possibility of cutting the last cable, allowing utilities to seamlessly deliver power as easily as information is now transmitted through the air [1-3].

Nowadays, WPT technology attracts much academic and business interest due to its user-friendly nature. Many academic studies have investigated the WPT application potential from small electronic devices, such as medical 
implants [4-11], irons, vacuum cleaners, televisions [12], and chip/transistor power supply [13], to larger high-power ones, such as power distribution [14-18], electric vehicles [19, 20], wireless-powered lighting systems [21], industrial robots [22, 23], space vehicles, and satellites [24-27]. Recently, new products have been launched focusing on contactless battery charging for mobile appliances (charging pads, phones, and laptops) [28-33] and, generally, on cord-free desks [34, 35]. The common ground of all these cases is that WPT technology will be more practical if its WPT configurations become more efficient, more high-power and capable of transferring power over significantly larger distances through the air [36]. Yet, there is no such WPT configuration to simultaneously satisfy the previous requirements.

More specifically, to configure WPT configurations, there are two implementation methods: the resonant inductive coupling method and the magnetic resonance coupling (MRC) method. The resonant inductive coupling method uses the electromagnetic wave. It is first recognized and exploited by Tesla [1, 32, 37-42]. Although it is an efficient nonradiative WPT method that can charge various electronic devices, the ambitious Tesla's goal of global power transfer through this method is utopian. As it has widely been verified, the resonant inductive coupling method is not suitable for realizing long-range high-power WPT configurations $[36,43]$. Conversely, the MRC method uses electromagnetic near-field waves combined with the coupled resonance phenomenon [3, 36, 44-53]. This method was essentially rediscovered and proposed in $[1,44,45,54]$. Actually, MRC method is characterized by its high power transfer efficiency (PTE) of approximately $90 \%$ within $1 \mathrm{~m}$ and, today, is suitable for practical short- and mid-range WPT configurations [36, $44,45,52,54-56]$.

In fact, MRC method becomes the epoch-making WPT technology establishing efficient WPT channels [57, 58]. The first-generation WPT configurations, which are widely used in daily activities, that are based on MRC method consists of two low-loss coupled resonators (i.e. the source and the load coupled resonators). Their source coupled resonator fills its surrounding environment with low-loss nonradiative magnetic fields oscillating at $\mathrm{kHz}$ or $\mathrm{MHz}$ frequencies [58]. The occurred nonradiative fields through their resonant nature allow high PTEs between the source and the load coupled resonators ensuring that the interaction with nonresonant objects of the surrounding environment is minimal. However, the coverage of these first-generation WPT configurations still remains limited. To increase the effectiveness of WPT configurations in long-range WPT applications, multiple coupled resonators are deployed between source and load coupled resonators extending their effective transfer distance [40, 43, 46, 52, 59-66].

The multiple coupled resonators can be deployed in various domino arrangements forming respective Domino Coupled Resonators (DCR) configurations. Among them, straight DCR configurations, which are studied in this paper, have the unique feature that their coupled resonators centers lie along the same transfer distance axis forming one main power flow path $[40,63]$. These DCR configurations enjoy higher PTEs for a given long-range transfer distance and higher application potential for power levels that range from few watts to many kilowatts in comparison with the limited uses of first-generation WPT configurations [40, 46, 52, 60, 62-65].

In assessing DCR configuration performance, the equivalent circuit approach is widely used in the literature [3, $31,52,67-69]$. In this paper, a theoretical analysis, which is based on the standard coupled circuit theory $[70,71]$ and the magnetoinductive resonator system analysis $[44,72]$, is analytically presented. On the basis of a small set of input parameters and a reduced number of WPT assumptions, the proposed theoretical analysis gives accurate results in terms of PTE when different DCR configurations are considered. Actually, the theoretical analysis is applied in order to unveil the DCR configuration key parameters and investigate their influence on PTE. The numerical results derived from the theoretical analysis are validated through a set of experimental measurements.

Although the proposed theoretical analysis accurately copes with the PTE behavior of DCR configurations, its main deficiency is its slow response when DCR configurations with a great number of coupled resonators are deployed. In order to facilitate the handling and to optimize the required computational time of these mid- and long-range DCR configurations, except for the accurate theoretical analysis, an approximate method is first proposed. This approximate method is denoted as chain scattering matrix (CSM) method and gives quick and reliable numerical results for practical DCR configurations. Its formulation is based on the scattering matrix [73-75] and ABCD matrix [24, 26] formalism while its high fidelity and accuracy is validated through the comparison of its numerical results with the respective experimentally validated results of the theoretical analysis.

Already mentioned in the literature [52, 64], a DCR configuration can be interpreted as an expansion of a power transformer, which consists of two coils. Recognizing the physical similarities between these two different systems [7678] and by exploiting the newly developed tools (i.e., the theoretical analysis and the approximate CSM method), the potential of replacing all step-down power transformers of power grid (i.e., power transformers that step down the supply voltage to a level suitable for the lower voltage level they feed) with practical DCR configurations is first proposed and investigated in this paper. Based on performance metrics such as PTE and transformation ratio (TR), that is, the percentage ratio of output to input voltage, it is reported that power transformers can comfortably be replaced with practical DCR configurations regardless of the power transformer typeeither high-voltage (HV)/medium-voltage (MV) or MV/lowvoltage (LV) or HV/LV power transformers.

DCR configurations and their potential of substituting power transformers can establish a new vision for future's smart grids. In fact, DCR configurations define a state-of-theart and convenient solution that cannot only substitute power transformers of the power grid but also can replace entire transmission line branches too. Therefore, DCR configurations constitute an important step towards the solution of last cable problem; say, the power delivery to either large or small 
customers eliminating the presence of power transformers and transmission line branches.

Anyway, WPT is a newly born technology that requires time, patience, and attention to become fully operational. Hence, apart from some technical issues concerning practical mid- and long-range high-power DCR configuration requirements for the power transformer replacement issue, a brief section is devoted to a research road map and some future steps that must be followed so that WPT technology and its promising DCR configurations become economically viable and technically feasible power grid solution. Finally, it is evident that the best performance results of future's smart grids concerning power transmission and distribution are ensured through the cooperative operation (cooperative power delivery) and further integration of DCR configurations with today's well-proven power grid infrastructure.

The rest of this paper is organized as follows. In Section 2, the transmission and distribution power grids are analytically presented. Special emphasis is given on the transmission lines and power transformers of power grid as well as the main advantages for adopting DCR configurations in order to replace these today's power grid components. Section 3 provides the entire analysis framework concerning the operation of DCR configurations: theoretical analysis, DCR configuration assumptions, approximate CSM method, and various approximations concerning WPT transmission and distribution. In Section 4, numerical results and discussion identify and assess the influence of specific DCR configuration design parameters on PTE and TR performance as well as the accuracy of theoretical analysis and approximate CSM method. The replacement potential of step-down power transformers and their transmission line branches with practical DCR configurations is thoroughly investigated. Section 5 includes background to ideas for future WPT works. Section 6 concludes this paper.

\section{Transmission and Distribution Power Grids}

The general principles of power generation, transmission, and distribution have been established more than a century ago. Incremental updates have been introduced in terms of renewable sources and other complex power electronic components. Generated electric power is transmitted to the load centres and consumers through this sophisticated network mainly consisting of transmission lines and power transformers [79-81].

2.1. Transmission Lines of Power Grid. Depending on the amount of carried power and its voltage level, a power grid can be further divided into two main interconnected power networks.

(i) Transmission Power Network. Its main purpose is to connect all major generator stations and critical load points in the energy system via loop structure. It comprises overhead HV transmission lines. This bulk supply energy system handles large power blocks allocating them among its available electrical energy corridors so that the best overall operating economy and/or other technical objectives are accomplished.

(ii) Distribution Power Network. It has the largest share in power grid since it comprises the finest meshes of power grid. Implemented in radial structure, it covers the power demands of medium large, residential, and commercial consumers. Distribution power network utilizes its overhead and underground infrastructure that consists of MV and LV transmission lines.

Although transmission lines determine a complete infrastructure network that encompasses power generation, transmission, and distribution capabilities, the required interconnection among different power networks is achieved through the combined use of transmission line branches and power transformers [79-85].

2.2. Power Transformers of Power Grid. Power transformers provide the required interconnections among the different functions of the power grid; more specifically, power grid performs three major functions.

(i) Power Generation. It is the first step in delivering electricity and is performed at power stations. Through the generating transformers, the generating voltages are stepped up and connected to the transmission power network. Generating (step-up) transformers are out of the scope of this paper.

(ii) Power Transmission. It is the second step in carrying electricity and involves the power transfer from generating transformers to $\mathrm{HV} / \mathrm{MV}$ substations, which comprise HV/MV transformers. At HV/MV transformers, the voltage is stepped down and power is fed into the distribution power network.

(iii) Power Distribution. It completes the power grid through delivering power to consumers. It involves the power transfer from HV/MV transformers to the primary and secondary distribution power networks.

(a) The primary distribution power network comprises MV/LV transformers and feeds power to medium-large consumers. In general, these MV/LV transformers are owned by the fed medium large consumers.

(b) The secondary distribution feeders consist of $\mathrm{MV} / \mathrm{LV}$ transformers that supply residential and commercial customers. These MV/LV transformers are owned by power utilities.

(c) In rare and remote cases of power distribution, either medium-large or residential or commercial customers can be straightforwardly supplied by HV/LV power transformers.

Note that HV/MV, MV/LV, and HV/LV power transformers are known as step-down power transformers and constitute the main interest of this paper $[24,25,43,62,86$, 87]. 
2.3. From Traditional Power Grid to WPT Systems. Due to their design, procurement, and manufacturing process, power transformers are custom-oriented equipment, entail significant capital expenditures and demand long lead times. In fact, the cost of a transformer is in the order of thousands of euros while its weight ranges from 100 to 400 tons. In addition, lead times could stretch beyond 20 months due to certain key parts and/or materials [86].

The impact of WPT systems on the way that power is transformed and delivered is immense. Instead of using power transformers, one can bring electrical power that is efficiently stepped down without the constraints of expensive, weighty and permanent electrical equipment. Inspired by relevant recent breakthroughs in WPT technology $[6,8$, $19,20,29,32,36,47,87-91]$, this paper tries to redefine the traditional power grid structure through the use of efficient WPT configurations that can replace step-down power transformers.

\section{Theoretical Analysis of DCR Configurations}

Until now, the main reason for the lack of WPT applications for mid- and long-range power transfer was their low PTE because all WPT efforts have focused essentially on Tesla's experiments and near-field coupling approaches-that is, one pair of coupled resonators-[1]. Recently, new interest has arisen in the field of WPT technology due to the fact that, instead of using one pair of coupled resonators, overall PTE can significantly be improved by using several coupled resonators placed in or near the short-range region where the PTE of coupled resonators is high [40, 52, 62-64, 88-91]. Furthermore, the use of a great number of coupled resonators can drastically increase the overall transfer distance between the excitation power source and the load achieving the required TR.

3.1. General DCR Configurations and Respective Theoretical Analysis. A DCR configuration may be considered as a cascade of magnetically coupled resonators, which are shown in Figure 1(a). These coupled resonators are placed in close proximity and they can be deployed in various domino arrangements. A practical DCR configuration is depicted in Figure 1(b).

Due to their design, DCR configurations are characterized by their high PTE efficiencies, permitting the delivery of a great number of WPT applications for power levels that range from few watts to several megawatts. As it has already been reported in $[60,62-64]$, the mathematical formulation that is usually employed to analyze these DCR configurations is based on the standard coupled circuit theory $[70,71]$ and the magnetoinductive resonator system analysis $[44,72]$.

More specifically, the general theoretical DCR configuration, which is used across this paper, is presented in Figure 2(a). This overall circuit configuration comprises the concatenation of $n$ coupled resonators. Each coupled resonator $i, i=1, \ldots, n$ consists of the serial connection of three subcomponents: its winding self-inductance $L_{i}$, its resistance $R_{i}$, and its winding compensating capacitance $C_{i}$.

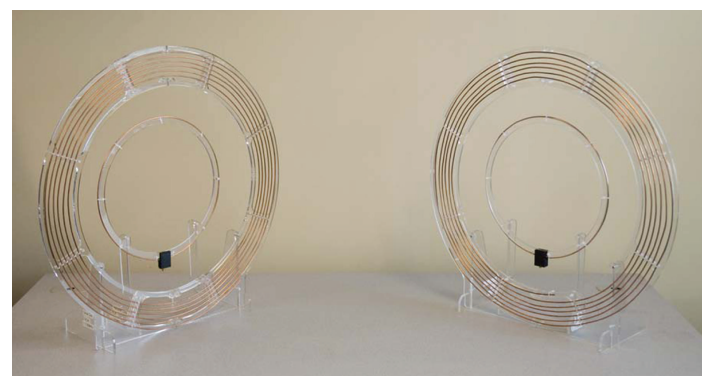

(a)

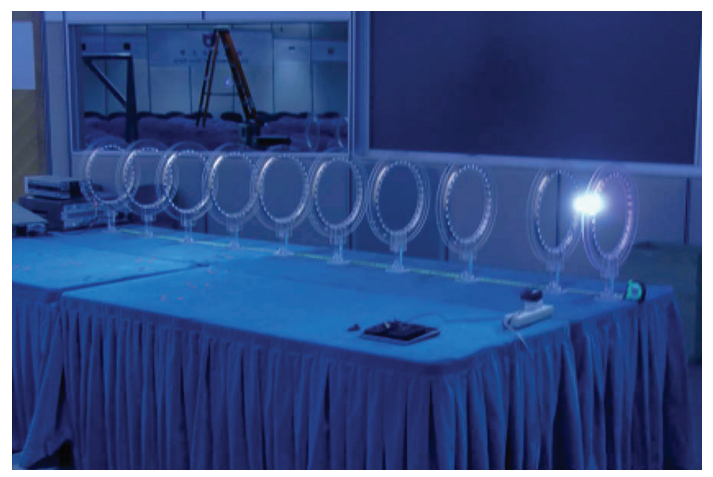

(b)

FIgure 1: (a) Practical coupled resonators [3]. (b) Practical DCR configuration with ten coupled resonators [62].

In particular, the first $(i=1)$ and last $(i=n)$ coupled resonators are denoted as source and load coupled resonators, respectively. Apart from their typical subcomponents, source coupled resonator also includes the source-that is, excitation voltage source $V_{S}$ with its impedance $Z_{S}$-whereas load coupled resonator includes the load-that is, impedance $Z_{L}$. To determine the aforementioned subcomponent parameters of coupled resonators, a plethora of analytical models has been proposed in the literature [4, 92-103]. Across this paper, the mathematical formulations of $[4,42,53,92,103]$ have been adopted due to their theoretical simplicity and their wellproven validity.

As it is clearly shown in Figure 2(a), each coupled resonator $i, i=1, \ldots, n$ provides path for a current $I_{i}$ to flow. The coupled resonator currents $\mathbf{I}^{\mathrm{DCR}}=\left[\begin{array}{lllll}I_{1} & \cdots & I_{i} & \cdots & I_{n}\end{array}\right]^{T}$ are determined through the following general circuit equation:

$$
\mathbf{A} \cdot \mathbf{I}^{\mathrm{DCR}}=\left[\begin{array}{ll}
-V_{S} & \mathbf{0}_{1 \times(n-1)}
\end{array}\right]^{T}
$$

where $[\cdot]^{T}$ denotes the transpose of a matrix, $\mathbf{0}_{m \times n}$ is an $m \times n$ matrix with zero elements, and $\mathbf{A}$ is $n \times n$ matrix depending on the frequency, coupled resonator characteristics, source and load impedances, and mutual inductances between coupled resonators $M_{i j}(i, j=1, \ldots, n, i \neq j)[40,52,60,62-64]$. It should be noted that (1) describes a DCR configuration that is not restricted to operate in its (self-) resonance frequency (for more details, see also in Section 4.1.5). 


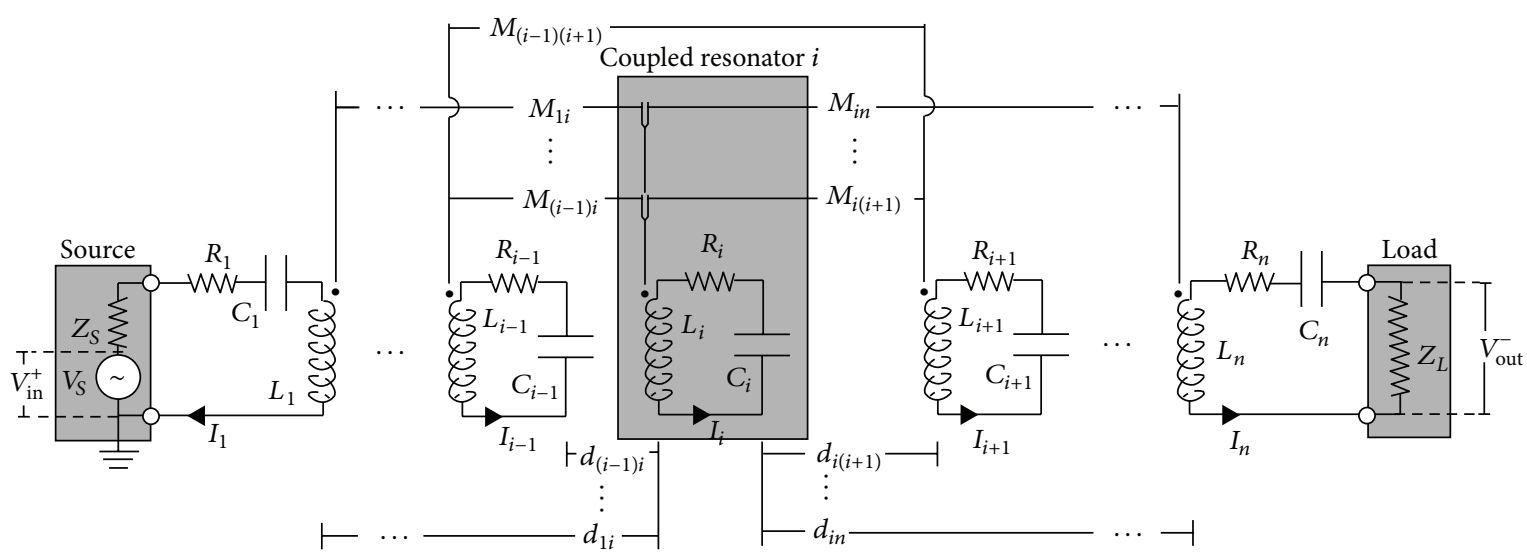

(a)

I

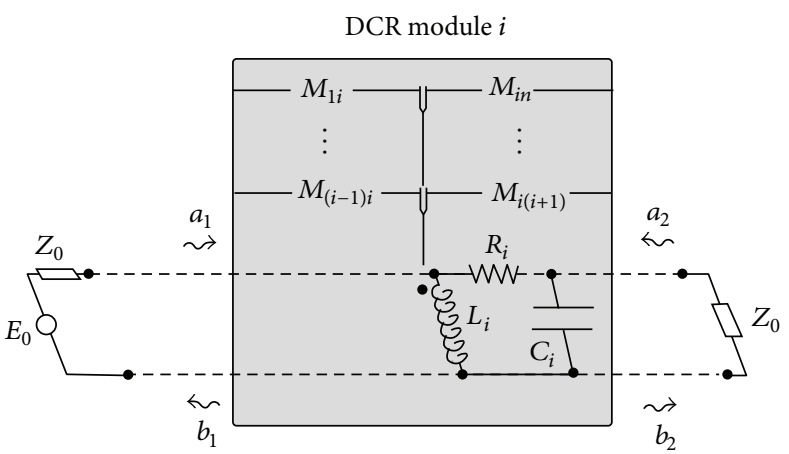

(b)

FIGURE 2: Typical DCR configuration with $n$ coupled resonators. (a) Equivalent circuit. (b) DCR module of approximate CSM method.

Under three assumptions concerning WPT to DCR configurations-see Section 3.2-PTE of the DCR configuration depicted in Figure 2(a) is given by

PTE

$$
=\left\langle\left\{\sum_{i=1}^{n-1}\left[\left|\frac{I_{i}}{I_{n}}\right|^{2} \cdot\left|\frac{R_{i}}{Z_{L}}\right|\right]\right\}+\left[\left|\frac{I_{1}}{I_{n}}\right|^{2} \cdot\left|\frac{Z_{S}}{Z_{L}}\right|\right]+\left|\frac{R_{n}}{Z_{L}}\right|+1\right\rangle^{-1} .
$$

Combining (1) and (2), it is easily verified that PTE mainly depends on mutual inductances between coupled resonators $M_{i j}(i, j=1, \ldots, n, i \neq j)$, coupled resonator resistances $R_{i}$, $i=1, \ldots, n$, source impedance $Z_{S}$ and load impedance $Z_{L}$ for a given DCR configuration, namely [62],

$$
\begin{aligned}
\mathrm{PTE}= & f\left(M_{12}, \ldots, M_{(i-1) i}, \ldots, M_{(n-1) n},\right. \\
& \left.R_{1}, \ldots, R_{i}, \ldots, R_{n}, Z_{S}, Z_{L}\right), \quad i=1, \ldots, n .
\end{aligned}
$$

It should be noted that the theoretical analysis of DCR configurations has experimentally been verified in $[40,52,60$, 62-64].

3.2. Assumptions Concerning WPT to DCR Configurations. To study the WPT behavior of DCR configurations, three assumptions are needed so that the theoretical analysis of these configurations will be facilitated without, however, losing its theoretical generality, namely the following.

(1) All the used coupled resonators are identical-that is, they consist of the same subcomponents presenting the same geometrical, material, and circuital characteristics-and they are placed in linear path in each DCR configuration - that is, they are coaxial.

(2) All the considered coupled resonators for a given CDR configuration are assumed to have the same selfresonant frequency in order to efficiently exchange power between them while dissipate little power to extraneous objects, namely,

$$
2 \pi f_{R} L_{i}-\frac{1}{2 \pi f_{R} C_{i}}=0, \quad i=1, \ldots, n,
$$

where $f_{R}$ is the self-resonance frequency (for more details, see also Section 4.1.5).

(3) Source and load impedances are assumed to be Ohmic resistances.

3.3. Simplified Approximation for Coaxial and Circular DCR Configurations. With reference to Figure 2(a), from (3) and by exploiting well-known Maxwell's equation to calculate mutual inductances of coaxial circular filamentary current loops $[57,62,104]$, PTE of a DCR configuration with $n$ 
coaxial and circular coupled resonators can be expressed as a function of the distances of every two coupled resonators $d_{i k}, i, k=1, \ldots, n, i<k$, the source impedance and the load impedance, namely $[40,52,60,62-64]$,

$$
\begin{array}{r}
\mathrm{PTE}=g\left(d_{12}, \ldots, d_{i k}, \ldots, d_{(n-1) n}, Z_{S}, Z_{L}\right) \\
i, k=1, \ldots, n, i<k .
\end{array}
$$

Actually, as it regards DCR configurations of interest in this paper, equal distance span $d_{\text {SPAN }}$ is assumed between adjacent coupled resonators. Thus, PTE of a DCR configuration with $n$ equally spaced coaxial and circular coupled resonators solely depends on the number of coupled resonators, the source impedance and the load impedance for a given transfer distance. Therefore, PTE of these DCR configurations can further be simplified to

$$
\mathrm{PTE}=h\left(n, d_{\mathrm{SPAN}}, Z_{S}, Z_{L}\right)
$$

3.4. Practical DCR Configurations and Approximate CSM Method. Until now, the theoretical analysis presented in Sections 3.1-3.3 can successfully deal with the peculiarities of the behavior of practical DCR configurations. However, its main problem, which is common to all relevant theoretical models of the literature $[40,52,60,62-64]$, is the size of the used mutual inductance matrices that hinders its practical implementation when a great number of coupled resonators needs to be deployed.

So far, several approximate methods with converging results have been used to determine the PTE of WPT systems $[14,21,24,26,73,105-109]$. In this paper, the CSM method is proposed, which constitutes a refined version of the scattering matrix method first presented in [73]. To apply the CSM method, a DCR configuration is separated into segmentsDCR modules, each of them comprising the successive coupled resonators encountered across the transfer distance-see Figure 2(b). The model used in the present work is based on the scattering matrix formulation introduced in [73-75] and alternatively used as ABCD matrix formulation $[24,26]$.

3.4.1. CSM Method and DCR Modules. WPT through the various DCR modules is taken into account through their respective CSMs. As depicted in Figure 2(b), a typical DCR configuration comprises three different types of DCR modules, namely the following.

(1) Source DCR Module. It is the first DCR module of a DCR configuration. With reference to Figure 2(a), the CSM of the source DCR module is given by

$$
\begin{aligned}
\mathbf{T}_{1} & =\mathbf{T}_{S}\left(V_{S}, Z_{S}, R_{1}, L_{1}, C_{1}, M_{12}, \ldots, M_{1 i}, \ldots, M_{1 n}\right) \\
& =\left[\begin{array}{ll}
T_{S, 11} & T_{S, 12} \\
T_{S, 21} & T_{S, 22}
\end{array}\right],
\end{aligned}
$$

where $T_{S, 11}, T_{S, 12}, T_{S, 21}$, and $T_{S, 22}$ are the elements of the $\mathbf{T}_{S}$ matrix.
(2) Load DCR Module. It is the last DCR module of a DCR configuration. With reference to Figure 2(a), the CSM of the source DCR module is given by

$$
\begin{aligned}
\mathbf{T}_{n} & =\mathbf{T}_{L}\left(Z_{L}, R_{n}, L_{n}, C_{n}, M_{1 n}, \ldots, M_{i n}, \ldots, M_{(n-1) n}\right) \\
& =\left[\begin{array}{ll}
T_{L, 11} & T_{L, 12} \\
T_{L, 21} & T_{L, 22}
\end{array}\right],
\end{aligned}
$$

where $T_{L, 11}, T_{L, 12}, T_{L, 21}$, and $T_{L, 22}$ are the elements of the $\mathbf{T}_{L}$ matrix.

(3) Coupled Resonator DCR Modules. There are $n-2$ coupled resonator DCR modules, that is, all the other DCR modules exclusive of source and load DCR modules. With reference to Figure 2(a), the CSM of a coupled resonator DCR module $i$ is given by

$$
\begin{array}{r}
\mathbf{T}_{i}=\mathbf{T}_{i}\left(R_{i}, L_{i}, C_{i}, M_{1 i}, \ldots, M_{(i-1) i}, \ldots, M_{i n}\right), \\
i=2, \ldots, n-1 .
\end{array}
$$

Since input and output terminations are assumed matched and having already determined the CSMs of the various DCR modules, the overall CSM of the DCR configuration considered is evaluated in the appropriate cascade rule order from $[74,75,110,111]$

$$
\mathbf{T}_{\text {overall }}=\left[\begin{array}{ll}
T_{11} & T_{12} \\
T_{21} & T_{22}
\end{array}\right]=\mathbf{T}_{S} \cdot \prod_{i=2}^{n-1} \mathbf{T}_{i} \cdot \mathbf{T}_{L}=\prod_{i=1}^{n} \mathbf{T}_{i},
$$

where $T_{11}, T_{12}, T_{21}$, and $T_{22}$ are the elements of the $\mathbf{T}_{\text {overall }}$ matrix.

The overall end-to-end scattering matrix is obtained from

$$
\begin{aligned}
\mathbf{S}_{\text {overall }} & =\left[\begin{array}{ll}
S_{11} & S_{12} \\
S_{21} & S_{22}
\end{array}\right] \\
& =\left[\begin{array}{cc}
\frac{T_{21}}{T_{11}} & T_{22}-\left(\frac{T_{21} T_{12}}{T_{11}}\right) \\
\frac{1}{T_{11}} & \frac{-T_{12}}{T_{11}}
\end{array}\right],
\end{aligned}
$$

where $S_{11}, S_{12}, S_{21}$, and $S_{22}$ are the elements of the $S_{\text {overall }}$ matrix.

With reference to (11) and Figure 2(a), the PTE of a DCR configuration is given by the $S_{21}$ element of the $S_{\text {overall }}$ matrix, that is,

$$
\begin{aligned}
\operatorname{PTE}= & \operatorname{PTE}\left(V_{S}, Z_{S}, Z_{L}, R_{1}, \ldots, R_{n}, L_{1}, \ldots, L_{n},\right. \\
& \left.C_{1}, \ldots, C_{n}, M_{12}, \ldots, M_{(i-1) i}, \ldots, M_{(n-1) n}\right) \\
= & \left|\frac{V_{\text {out }}^{-}}{V_{\text {in }}^{+}}\right|^{2}=\left|S_{21}\right|^{2}=\left|T_{11}\right|^{-2},
\end{aligned}
$$

where $V_{\text {out }}^{-}$and $V_{\text {in }}^{+}$are the reflected load voltage and the incident source voltage wave, respectively,-see Figure 2(a)when the incident wave $a_{2}$ of load module and the reflected wave $b_{1}$ of source is equal to zero, respectively, that is, the output and input termination is matched, respectively, which has already been assumed $[74,75,110,111]$. 
3.4.2. Approximate CSM Method and Coaxial and Circular DCR Configurations. As it has already been demonstrated in Section 3.4.1, CSM method is a general methodology that can determine the PTE of any DCR configuration in a straightforward way. However, the practicability of (12) remains limited in WPT systems and especially in DCR configurations of this paper due to its complex dependencies on various DCR configuration parameters. To enhance its applicability, approximate CSM method is proposed that comes from CSM method when a number of simplifications are applied, namely the following.

(i) In accordance with assumption 1 of Section 3.2, from (10), the overall CSM is simplified to

$$
\mathbf{T}_{\text {overall }}^{\prime}=\mathbf{T}_{S} \cdot \mathbf{T}_{i}^{\prime n-2} \cdot \mathbf{T}_{L}
$$

(ii) Due to their structure and with satisfactory accuracy, DCR modules can be approximated as reciprocal (symmetrical), loss-free, and perfectly matched transmission components $[24,26,73-75,110,111]$. Thus, the overall CSM of (13) can be further simplified to

$$
\begin{aligned}
\mathbf{T}_{\text {overall }}^{\prime} & =\left[\begin{array}{cc}
T_{11}^{\prime} & T_{12}^{\prime} \\
T_{21}^{\prime} & T_{22}^{\prime}
\end{array}\right]=\mathbf{T}_{S} \cdot \mathbf{T}_{i}^{\prime n-2} \cdot \mathbf{T}_{L} \\
& \cong\left[\begin{array}{cc}
T_{S, 11} \cdot T_{i, 11}^{\prime n-2} \cdot T_{L, 11} & 0 \\
0 & T_{S, 22} \cdot T_{i, 11}^{\prime-(n-2)} \cdot T_{L, 22}
\end{array}\right],
\end{aligned}
$$

where $T_{11}^{\prime}, T_{12}^{\prime}, T_{21}^{\prime}$, and $T_{22}^{\prime}$ are the elements of the $\mathbf{T}_{\text {overall }}^{\prime}$ matrix and $T_{i, 11}^{\prime}, T_{i, 12}^{\prime}, T_{i, 21}^{\prime}$, and $T_{i, 22}^{\prime}$ are the elements of the $\mathbf{T}_{i}^{\prime}$ matrix.

(iii) Based on (12) and the transmission-line-like approximated CSM of (14), the approximated PTE of a DCR configuration with $n$ coupled resonators and distance span $d_{\text {SPAN }}$ is determined from

$$
\mathrm{PTE}_{\text {approx }, n}=\left|T_{11}^{\prime}\right|^{-2}=\left|T_{S, 11} \cdot T_{i, 11}^{\prime n-2} \cdot T_{L, 11}\right|^{-2} .
$$

(iv) Equation (15) can further be simplified in a flowchart procedure through the following simple cascade rule:

$$
\begin{gathered}
\mathrm{PTE}_{\text {approx }, n}=\underbrace{\mathrm{PTE}_{\text {approx }, 2} \cdot\left|T_{i, 11}^{\prime}\right|^{-2 \cdot(n-1-2)}}_{\mathrm{PTE}_{\text {approx }, n-1}} \cdot\left|T_{i, 11}^{\prime}\right|^{-2} . \\
=\mathrm{PTE}_{\text {approx }, 2} \cdot\left|T_{i, 11}^{\prime}\right|^{-2 \cdot(n-2)}, \quad n>2, \\
\mathrm{PTE}_{\text {approx }, 2}=\mathrm{PTE}_{\text {approx }, 1} \cdot\left|T_{L, 11}\right|^{-2}, \quad n=2, \\
\operatorname{PTE}_{\text {approx }, 1}=\left|T_{S, 11}\right|^{-2}, \quad n=1,
\end{gathered}
$$

where $\left|T_{i, 11}^{\prime}\right|^{-2}$ practically describes the additional PTE that should be taken into consideration when one new DCR module is inserted, thus, expanding the existing DCR configuration.
3.5. DCR Configurations and Other Practical Issues. Although higher voltage levels can be achieved by simply increasing the source excitation voltage of DCR configurations, more effective than usual heat-dissipation methods are needed so as to prevent the source-that is, source transistorsfrom overheating, package and insulation breakdowns and damage. More specifically, in the case of WPT in HV and in MV applications, the supported power levels require forced air or water cooling on the source coupled resonator so that its temperature remains below $70^{\circ} \mathrm{C}[18,67]$. As it concerns the heat losses of inductances and capacitances, a temperature increase at these components is not critical since they are passive components and are more resilient to the heat. However, the use of insulation oil can mitigate any potential thermal risks.

Except for the aforementioned overheating issues, midand long-range WPT technology is not only power lossy but also source and victim of electromagnetic interference (EMI) from and to external resonators, respectively. Since WPT is achieved through DCR configurations, appropriate shielding at the expense of thickness and weight should be adopted. The use of shield permits the system to be more EMI robust in environments where magnetic fields of nearby external resonators may interact with the magnetic field of coupled resonators of DCR configurations. However, shielding is beyond the scope of this paper. Hence, it is assumed that DCR configurations operate in environments free of external resonators that can critically degrade the PTE of DCR configurations $[57,67,112]$.

In addition, at high frequencies, the behavior of coupled resonators of DCR configurations becomes different from their ac low-frequency behavior. Actually, skin and proximity effects affect the coupled resonator behavior and are responsible for resonant frequencies. In order to obtain more accurate results applying CSM method at frequencies above several hundred $\mathrm{kHz}$ or $\mathrm{MHz}$, the prediction of suitable highfrequency correction terms for the three subcomponents of each DCR module (such as stray capacitance) is crucial for the design of high-frequency DCR configurations [4, 92-103].

Finally, as it has already been mentioned, today's WPT technology mainly utilizes electromagnetic near-field waves while DCR configurations further exploits MRC phenomenon [3, 32, 36, 44-53]. Especially, this phenomenon facilitates the WPT of great quantities of power at mid- and long-range distances. However, this long-range high-power WPT unrests about its harmful results that they could cause to human health [12]. In accordance with [61, 105, 113], WPT should comply with EMI and electromagnetic compatibility (EMC) regulations that impose safety levels with respect to human exposure to the used radio frequency electromagnetic fields.

\section{Numerical Results and Discussion}

The numerical results of various types of DCR configurations aim at investigating (a) their PTE in relation with specific DCR configuration design parameters; (b) the efficacy and accuracy of describing DCR configurations through 
TABLE 1: Nominal parameter values of the practical coupled resonators.

\begin{tabular}{lcccccc}
\hline $\begin{array}{l}\text { Radius of coupled } \\
\text { resonator coils } \alpha(\mathrm{mm})\end{array}$ & $\begin{array}{c}\text { Number of } \\
\text { coil turns } N_{\alpha}\end{array}$ & $\begin{array}{c}\text { Radius of } \\
\text { wires } R(\mathrm{~mm})\end{array}$ & $\begin{array}{c}\text { Layers of } \\
\text { the wire } N_{d}\end{array}$ & $\begin{array}{c}\text { Load impedance } \\
Z_{L}(\Omega)\end{array}$ & $\begin{array}{c}\text { Self-resonance } \\
\text { frequency } f_{R}(\mathrm{kHz})\end{array}$ & $\begin{array}{c}\text { Copper electrical } \\
\text { conductivity } \sigma(\mathrm{MS} / \mathrm{m})\end{array}$ \\
\hline 155 & 11 & 1.2 & 1 & 17 & 530 & 59.6 \\
\hline
\end{tabular}

TABLE 2: Two DCR configuration scenarios with their nominal parameter values.

\begin{tabular}{lccccc}
\hline & $\begin{array}{c}\text { Transfer distance } d \\
(\mathrm{~m})\end{array}$ & $\begin{array}{c}\text { Number of coupled resonators } n \\
(\mathrm{~m})\end{array}$ & $\begin{array}{c}\text { Distance span } d_{\text {SPAN }} \\
(\mathrm{m})\end{array}$ & $\begin{array}{c}\text { Source voltage } V_{S} \\
(\mathrm{~V})\end{array}$ & $\begin{array}{c}\text { Source impedance } Z_{S} \\
(\Omega)\end{array}$ \\
\hline Scenario A & 0.6 & 3 & 0.3 & 220 & 3.45 \\
Scenario B & 0.9 & 4 & 0.3 & 220 & 1.42 \\
\hline
\end{tabular}

the approximate CSM method; (c) the potential of power transformer replacement with practical DCR configurations; and (d) minimum and maximum WPT distances that practical DCR configurations can cover for a given TR.

To study the behavior of DCR configurations, practical circular and coaxial coupled resonators have been chosen from the literature. The following theoretical studies are conducted based on the parameters of these practical coupled resonators, which have been experimentally verified in [ 40 , $52,60,62-64]$, that are reported in Table 1.

4.1. Design of High-PTE DCR Configurations. To achieve a high PTE for practical DCR configurations, a wealth of DCR configuration design parameters is required to be appropriately adjusted. Towards that direction, several parameters of them are identified and investigated in terms of their impact on PTE of DCR configurations, namely: the radius of coupled resonator coils, the number of coil turns, the radius of the used wires in coils, the number of coupled resonators for a given transfer distance, the operating frequency, and the source and the load impedances.

As it concerns the simulations of this subsection, except for the nominal parameter values that are detailed in Table 1 , two different DCR configuration scenarios-that is, DCR configuration scenario, $\mathrm{A}$ and $\mathrm{B}$-are used whose additive nominal parameter values are reported in Table 2.

In accordance with Tables 1 and 2, these two scenarios have been carefully chosen so that the numerical results of the theoretical analysis of Sections 3.1-3.3 will be also experimentally validated by a trial of experimental measurements, which has been presented in [62].

4.1.1. Radius of Coupled Resonator Coils. It is well known that coil dimensions and coil shapes critically affect the magnitude and distribution of their occurred magnetic fields. In fact, these fields are closely related to the PTE of magnetoinductive resonator systems. More specifically, the radius of coupled resonator coils plays significant role towards efficient WPTs in DCR configurations since power is mainly transferred over relatively short distances, which are on the order of this radius [44, 45, 54, 114-117].

In Figure 3, PTE is plotted versus the radius of coupled resonator coils for DCR configuration scenarios A and B. In the same figure, PTE of these two DCR configuration scenarios is also shown with its corresponding experimental

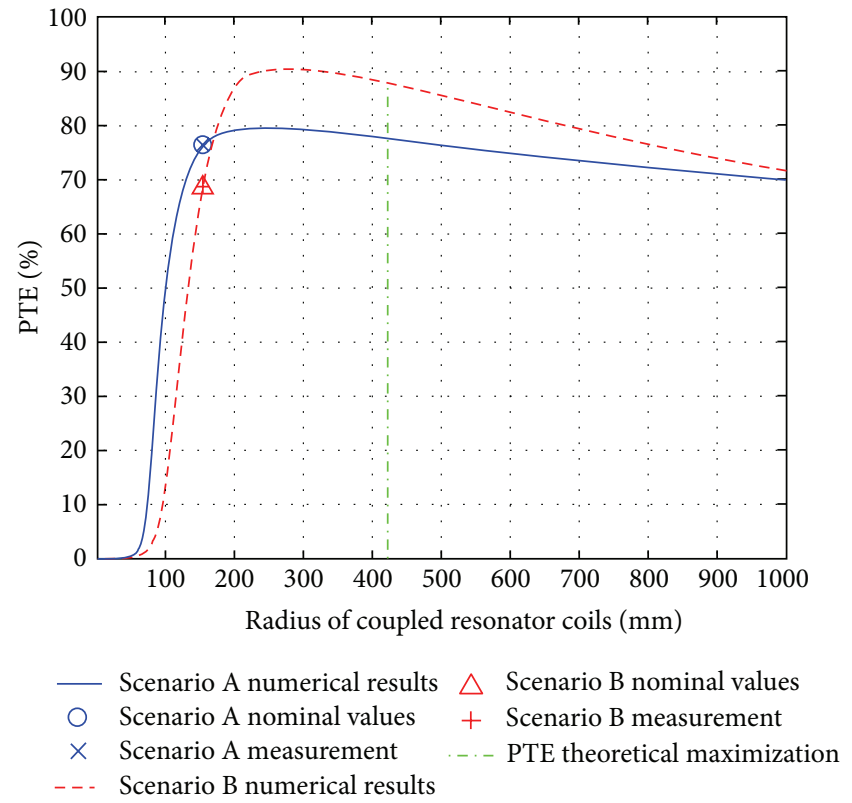

FigURE 3: PTE versus coupled resonator coil radius for two different DCR configuration scenarios.

measurements when the nominal value of coupled resonator coil radius is considered-that is, $a=155 \mathrm{~mm}$.

It is clearly shown that, when the radius of coupled resonator coils becomes larger, PTE increases till a maximum point and, then, smoothly tends to zero regardless of the adopted DCR configuration. This PTE behavior is explained through the analysis of occurred magnetic fields across DCR configuration transfer path; in a single circular coil with radius $\alpha$, the magnetic field strength is maximized at distance $\sqrt{2} a / 2$ along its coil axis $[4,118]$. In the case of DCR configurations, the coil axes of coupled resonators coincide with the DCR configuration transfer path. Similarly to the simple case, PTE maximization occurs when the distance span is approximately equal to this magnetic field maximization distance. Note that this result may imply a reverse design procedure so that the optimum radius of coupled resonator coils can be determined; for example, with reference to Figure 3 and for the nominal distance span $\left(d_{\text {SPAN }}=0.3 \mathrm{~m}\right)$, the PTE maximization occurs when the coupled resonator coil radius is approximately equal to $a_{\mathrm{MAX}}=2 \cdot d_{\mathrm{SPAN}} / \sqrt{2} \cong 424 \mathrm{~mm}$, regardless of the adopted DCR configuration scenario. 
Furthermore, a physical constraint exists that determines either the upper boundary of coupled resonator coil radius or the elegant PTE transition to zero; when the coupled resonator coil radius increases, its coil circumference tends to become comparable to the wavelength. Hence, above a coil radius threshold, coupled resonator currents present non uniform distributions having negative impact on their PTE performance and explaining the curve form of Figure 3 [57].

4.1.2. Number of Turns of Coupled Resonator Coils. An effective way to increase the useable range of coupled resonator coils and, thus, PTE of a DCR configuration is to add multiple turns to the coupled resonator coils. As shown in $[26,92,119]$, increasing the number of coil turns $N_{\alpha}$, mutual inductance between coupled resonators increases quadratically with $N_{\alpha}$.

In Figure 4, PTE is plotted versus the number of turns of coupled resonator coils for DCR configuration scenarios $A$ and B. In the same figure, PTE of these two DCR configuration scenarios is also shown with its corresponding measurements when the nominal value of their coupled resonator coil turn number is considered-that is, $N_{\alpha}=11$.

Observing Figure 4, it is obvious that as the number of turns becomes higher, PTE increases till a maximum point and, then, decreases to zero regardless of the adopted DCR configuration; by only adjusting the number of coil turns in coupled resonators, the DCR configuration PTE can significantly be improved. In practice, this technique can become useful in future since it allows the power utilities to easily design high efficient WPT systems for mid- and longrange applications [120].

Nevertheless, the physical constraint that defines the PTE maximum with respect to the number of coil turns is related with the ohmic losses; as the number of coil turns increases, so do the conductor length and the respective ohmic losses of each coupled resonator coil. This additive loss becomes critical preventing continuous increases in PTE of practical DCR configurations.

4.1.3. Radius of the Used Wires in Coupled Resonator Coils. In accordance with Section 4.1.2, the achievement of admissible PTEs for a given DCR configuration presupposes resistance reduction of used coupled resonator coils. An effective technique towards this reduction of coupled resonator coil resistance is the cross-section extension of their coil wires.

In Figure 5, PTE is plotted versus the radius of the used wires of coupled resonator coils for DCR configuration scenarios A and B. In the same figure, PTE of the two DCR configuration scenarios is also drawn as well as the corresponding measurements when the nominal value of the radius of their coupled resonator coil wires is consideredthat is, $R=1.2 \mathrm{~mm}$.

From Figure 5, it is evident that the radius increase entails a corresponding PTE increase. However, this PTE increase is marginal after several $\mathrm{mm}$ of wire radius due to the skin effect [121]. Actually, except for this PTE marginal increase, the unrestrained increase of wire radius causes enlargement of coupled resonator coil sizes. In many designs of practical

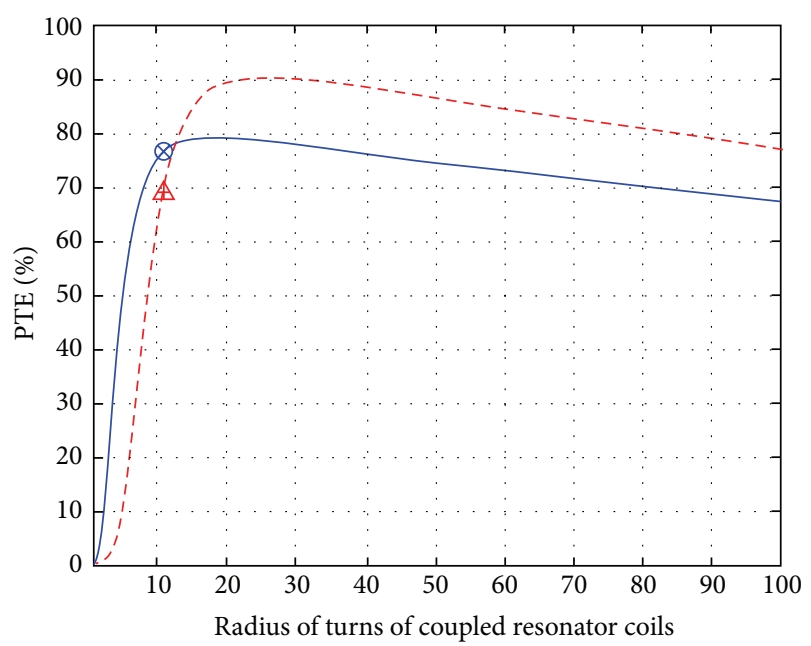

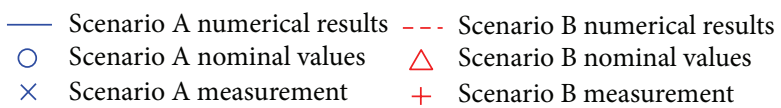

FIGURE 4: PTE versus number of turns of coupled resonator coils for two different DCR configuration scenarios.

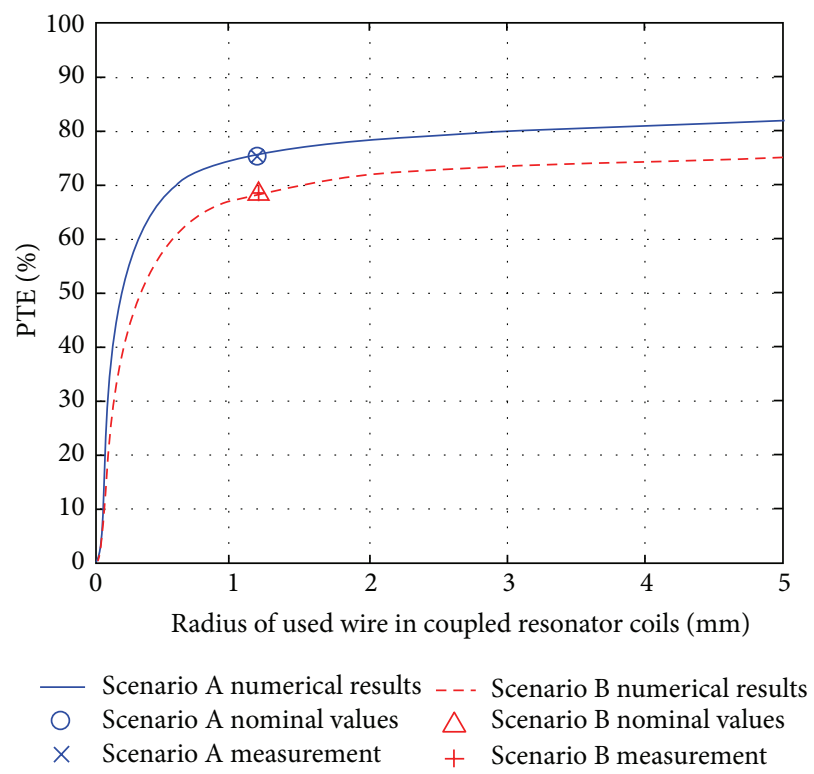

FIGURE 5: PTE versus radius of the used wire in coupled resonator coils for two different DCR configuration scenarios.

DCR configurations, there are certain dimensional limitations that restrict this coupled resonator coil configuration increase. Due to this fact, during the estimation of coupled resonator coil resistance, the coupled resonator coil dimensions must be first specified, and then the resistance of the used coil is derived in relation with (i) radius of coils-see Section 4.1.1; (ii) its number of coil turns-see Section 4.1.2; (iii) coil inductance; and (iv) maximum radius of used coil wires [121].

4.1.4. Number of Coupled Resonators. As it has already been presented in Sections 4.1.1-4.1.3, the WPT characteristics of 


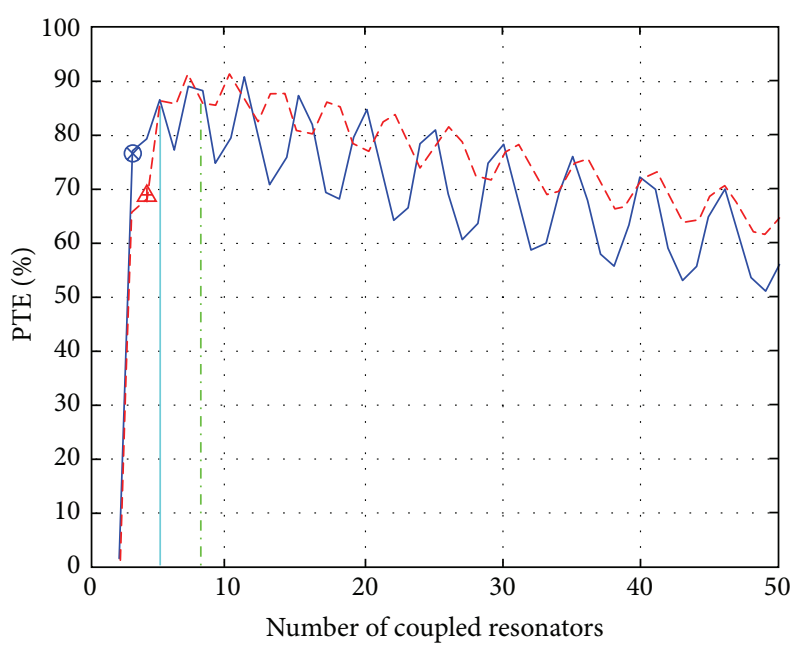

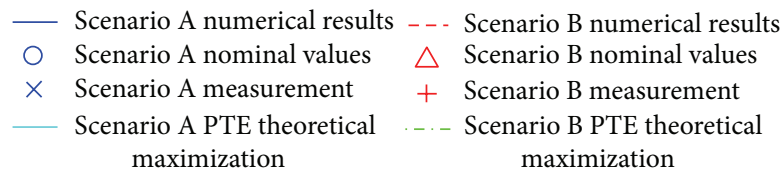

FIGURE 6: PTE versus coupled resonator number for two different DCR configuration scenarios.

a DCR configuration can be predicted and optimized through the presented theoretical analysis. This is feasible through the appropriate adjustment of the related coupled resonator inherent properties. Nonetheless, the aforementioned PTE findings of Sections 4.1.1-4.1.3 should be taken into consideration during the phase of DCR configuration design. This operation restriction reduces their practicability and applicability in the already installed WPT systems.

In order to overcome the low PTE of mid- and longrange applications without, however, substituting the already installed DCR configurations, a significant number of potential solutions have been proposed $[62,89,122]$. Among these proposals, this that has attracted the recent attention due to its promising PTE results in mid- and long-range applications is the insertion of extra coupled resonators. The additional as well as the existing coupled resonators are rearranged across the existing DCR configuration transfer path so as to achieve higher PTEs.

In Figure 6, PTE is plotted versus the number of coupled resonators for a given transfer distance when the DCR configuration scenarios $\mathrm{A}$ and $\mathrm{B}$ are applied. In the same figure, PTE of the two DCR configuration scenarios is also plotted with their corresponding measurements when the nominal values of the number of coupled resonators are considered-that is, $n=3$ and $n=4$ for DCR configuration scenarios A and $\mathrm{B}$, respectively.

Figure 6 reveals that low PTE can be mitigated by simply adjusting the number of coupled resonators and, thus, the distance span of DCR configurations. Similarly to the PTE theoretical maximization of Figure 3, the PTE maximization occurs when the distance span is equal to the magnetic field maximization distance that is equal to $\sqrt{2} a / 2$ or approximately $110 \mathrm{~mm}$, when DCR configuration scenario

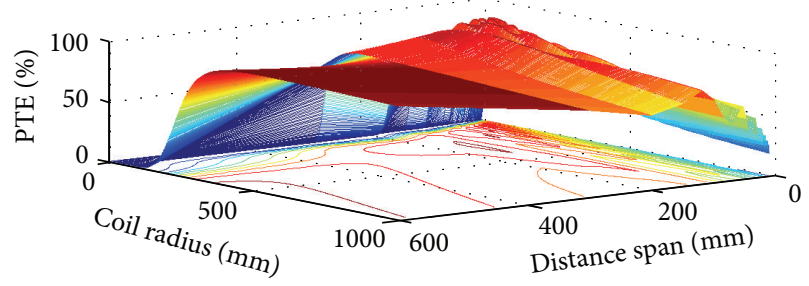

(a)

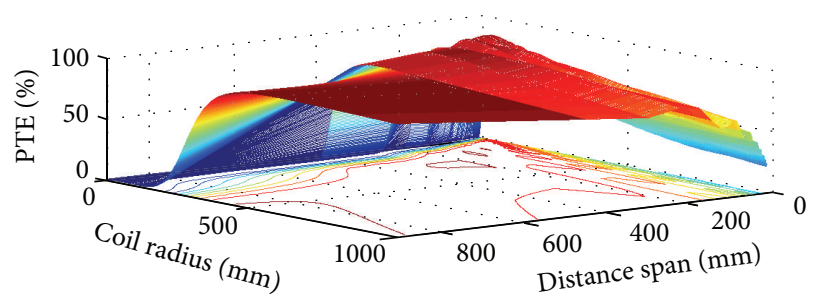

(b)

FIgURE 7: PTE versus coupled resonator coil radius and distance span. (a) DCR configuration scenario A. (b) DCR configuration scenario B.

properties are considered. Since the distance span and the transfer distance are known, this entails that the number of coupled resonators is approximately equal to 5 and 8 for DCR configuration scenarios $\mathrm{A}$ and $\mathrm{B}$, respectively. The respective PTE theoretical maximization curves for the two DCR configuration scenarios are also depicted in Figure 6. Note that slight divergences in Figures 3 and 6 between numerical and theoretical results come from the cumulative magnetic field effect of domino arrangements of coupled resonators in contrast with the single resonator coil consideration.

As it is observed from Figure 6, apart from the concativity of PTE curves with respect to the number of coupled resonators, another interesting remark of these curves is the existence of fluctuations on them. In general, an HF-band DCR configuration presents impedance variations because its mutual coupling coefficients significantly change with respect to the distance span; as the distance span decreases, the mutual coupling coefficients averagely increase [123, 124].

Actually, the effect of impedance mismatch averagely increases with respect to the number of coupled resonators. This is due to the fact that the reflected impedance presents important changes depending on the coupling degree that is related to the number of coupled resonators. Therefore, the coupling degree fluctuations cause respective fluctuations on PTE curves. Indeed, based on (6) and assumption 1 of Section 3.2, this PTE behavior is justified because it mainly depends on the number of coupled resonators and on impedance mismatches, which are incorporated into the theoretical model by the presence of source and load impedances.

Comparing Figures 3 and 6, an interesting trade-off between the coil radius of coupled resonators and the number of coupled resonators can be proposed. More specifically, in Figures 7(a) and 7(b), PTE is plotted versus the coil radius of coupled resonators and the distance span of coupled resonators for a given transfer distance when DCR 
configuration scenarios A and B are examined, respectively. In fact, the mutual coupling decreases when lower coil radii and larger distance spans are applied. This behavior implies a corresponding decrease in PTE performance of DCR configurations. Thus, for given coil radius, PTEs that are greater than $80 \%$ can only be achieved if the distance span is slightly larger, equal or slightly smaller than the coil radius $\left(d_{\text {SPAN }} / a \in\left[\begin{array}{ll}0.75 & 1.25\end{array}\right)\right.$. At very large air gaps $\left(d_{\text {SPAN }} / a \gg 1\right)$, PTE rapidly decreases permitting only a low amount of power to be delivered or a low duty cycle operation to be performed. Nowadays, this low PTE operation, which is also called highQ coupling, is often adopted at practical today's WPT systems with high number of turns of their coupled resonator coils $[2,3,52]$.

In pure electromagnetic terms, PTE behavior can be explained through the analysis of the coupled resonator electric field, namely $[54,125]$ : (i) the distance span is smaller than the coil radius: the electric field follows a Hankelfunction form. This function is characterized by its initial exponential-like regime and its long tails compared to the coil radius; (ii) the distance span is higher than the coil radius: the function of electric field is characterized by its oscillatory/radiation regime. This entails that power is slowly leaking out of the resonator coil.

Consequently, the distance span can be selected so as to be either shorter or larger than the common coupled resonator coil radius. Nonradiative energy between two coupled resonators can be transferred through the coupling of their resonant-field evanescent tails in both cases [55]. The crucial decision is to select an efficient combination of distance span and wire radius based on practical requirements in order to balance PTE and DCR configuration practicability [58].

4.1.5. Operating Frequency. The nonradiative MRC approach, which is followed in DCR configurations, presents serious potential to deliver power more efficiently in comparison with the traditional lower frequency inductive systems [44, $54,67,103,126-129]$. In accordance with a plethora of recent papers and various experimental verifications $[3,36,54,68$, 126], better PTE performance can be achieved through the use of higher frequencies at $\mathrm{kHz}$ or several $\mathrm{MHz}$ range.

In Figure 8, PTE is plotted versus the operating frequency for the DCR configuration scenarios A and B. In the same figure, PTE of the two DCR configuration scenarios is also drawn as well as the corresponding extended set of measurements when their self-resonance frequency is consideredthat is, $f_{R}=530 \mathrm{kHz}[62]$.

In Figures 9(a) and 9(b), PTE is plotted versus the operating frequency and distance span when DCR configuration scenarios A and B is applied, respectively.

Observing Figures 8, 9(a) and 9(b), several interesting remarks can be pointed out.

(i) In the case of traditional WPT systems that use resonant inductive coupling method, operation frequency is fixed with respect to their transfer distance [57]. On the contrary, for the WPT systems that follow MRC method such as DCR configurations studied in this paper, resonant frequency varies with respect

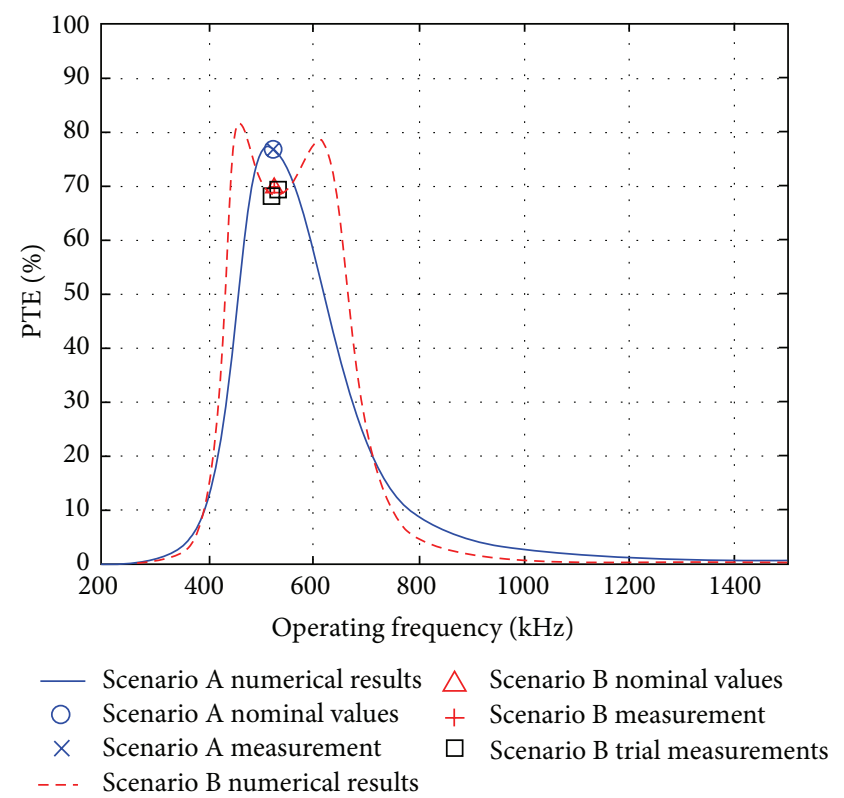

FIGURE 8: PTE versus operating frequency for two different DCR configuration scenarios.

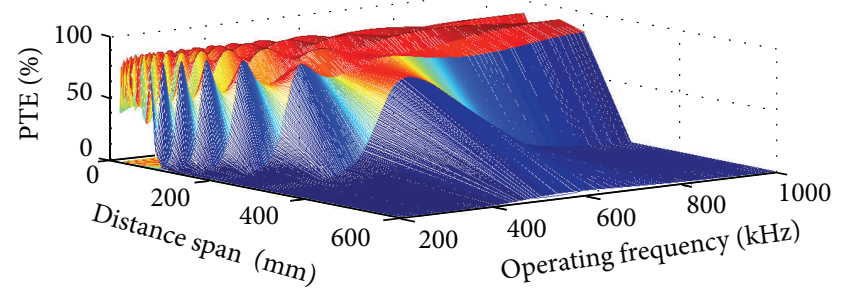

(a)

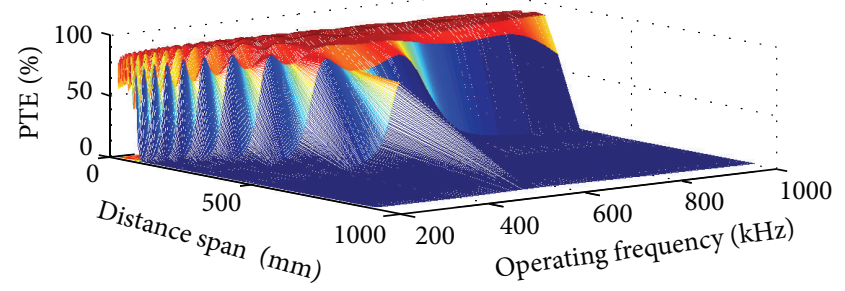

(b)

FIgURE 9: PTE versus operating frequency and distance span. (a) DCR configuration scenario A. (b) DCR configuration scenario B.

to their transfer distance. However, during practical implementations of WPT systems, the available operation frequencies are imposed by the regulation authorities. Hence, in order to maintain resonant frequency stable, winding compensating capacitances should be adaptively tuned.

(ii) Resonant frequency of DCR configurations may differ from the self-resonant frequency of their coupled resonators. In fact, resonant frequency is obtained when the resonant frequency of the odd and the even 
mode is already known (the two PTE maxima of DCR configuration scenario B of Figure 8) [57].

(iii) As the distance span between coupled resonators increases, the respective coupling decreases. This has as result that the frequency separation that describes the difference between odd and even modes also decreases. This frequency separation reduction continues till the two maxima converge at one (see the sole PTE maximum of DCR configuration scenario A of Figure 8). The operating frequency where the PTE maximization occurs is denoted as the critical coupling point and represents the farthest distance at which maximum PTE still remains achievable-see Figures 9(a) and 9(b) [3].

(iv) When several coupled resonators are deployed and the distance span becomes very small compared to the coupled resonator coil radius, multimode operation is exited in DCR configurations. This operation type is characterized by its great number of PTE maxima at low distance spans in the examined DCR configuration scenarios-see Figures 9(a) and 9(b).

(v) PTE can be improved over a wider range of coupled resonator properties if operating frequency is opted with the other DCR configuration properties. It is noted that the optimal operation frequency can be higher or lower than the resonance frequency depending on DCR configuration properties [63]. Anyway, slight shift from the optimal operation frequency could either increase or decrease PTE critically.

(vi) Combining Figures 7(a) and 7(b) with Figure 8, it can be reported that if the distance span is smaller than the coil radius then DCR configuration operation is considered as overcoupled and it results in maximum PTE. Conversely, when the distance span is higher than the coil radius, DCR configuration operation can be considered as undercoupled having as a result that the amount of power delivered to the load precipitously attenuates with distance (see also Figure 6). With reference to [3], near-constant PTE can be achieved versus distance if the suitable operation frequency is successfully identified for given distance span.

(vii) PTE differences between numerical results and experimental measurements are attributed to the used mathematical formulations and the occurred slight divergences in DCR configuration scenario parameters used in order to determine the subcomponents of coupled resonators.

4.1.6. Source and Load Impedances. Already mentioned in Section 4.1.4, as the number of coupled resonators increases for a given transfer distance, the greater the coupling coefficient and the impedance mismatch become. Conversely, with reference to Figure 8, the profound cause of the existence of more-than-one resonance frequencies, which permits multiple maximum PTEs over very short distance spans, is

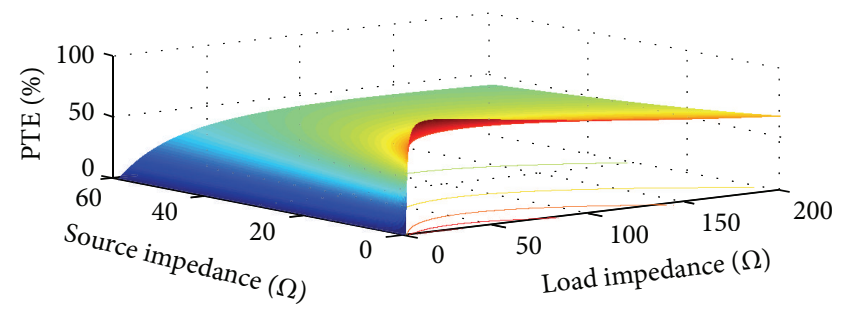

(a)

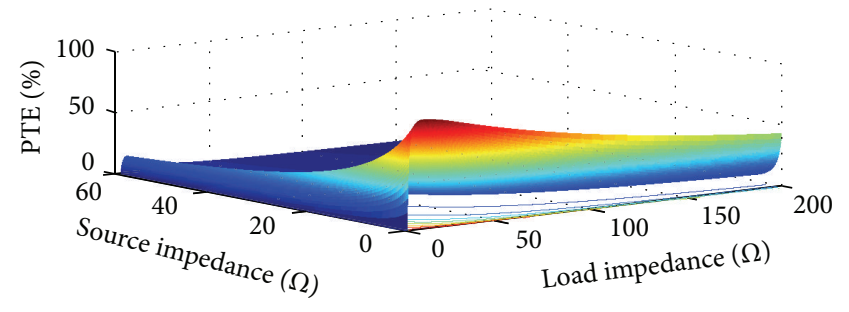

(b)

FIgURE 10: PTE versus source and load impedances. (a) DCR configuration scenario A. (b) DCR configuration scenario B.

the presence of impedance mismatches in DCR configurations $[123,130,131]$. Therefore, PTE of DCR configurations can be optimized by simply regulating impedance mismatches either in source or in load coupled resonators.

In Figures 10(a) and 10(b), PTE is plotted versus the source and load impedances when DCR configuration scenarios A and B are applied, respectively.

From Figures 10(a) and 10(b), certain thoughts can be expressed, namely, as follows.

(i) Similarly to other communications systems, the concept of WPT impedance matching, that is, the adjustment of the ratio between source and load impedance, is conducted using variable capacitances-such as winding compensating capacitances of Figure 2(a)and inductances in order to maintain high PTE [25].

(ii) In the majority of today's WPT systems, their reported PTE is between $30 \%$ and $50 \%$ [4, 132]. Recently, interesting feedback approaches that study the effect of loading on maximizing the PTE of WPT systems have been proposed improving PTE performancethat is, PTE can range above $70 \%[69,133-135]$.

(iii) By introducing the concept of impedance matching, new parameters concerning the design of DCR configurations are added. Now, the load problem is beneficially decoupled from the optimization process of the remaining DCR configuration parameters [133, 136]. Actually, there exists an optimum combination of source and load impedances for which PTE is maximized but resorted to numerical methods to find this optimum set. The presented approach which verifies the findings of the theoretical analysis - see (3) achieves maximum PTEs greater than $80 \%$ offering significant performance advantage in practical DCR configuration realizations. 
TABLE 3: Design parameters and the two DCR configuration scenarios: PTE and nominal and optimal parameter values.

\begin{tabular}{|c|c|c|c|c|}
\hline & \multicolumn{2}{|c|}{ Scenario A } & \multicolumn{2}{|c|}{ Scenario B } \\
\hline & Nominal values & Optimal values & Nominal values & Optimal values \\
\hline $\begin{array}{l}\text { Radius of coupled resonator coils } \\
\text { (Section 4.1.1)/PTE }\end{array}$ & $155 \mathrm{~mm} / 76.38 \%$ & $230 \mathrm{~mm} / 79.24 \%$ & $155 \mathrm{~mm} / 68.53 \%$ & $272 / 90.47 \%$ \\
\hline $\begin{array}{l}\text { Number of turns of coupled resonator coils } \\
\text { (Section 4.1.2)/PTE }\end{array}$ & $11 / 76.38 \%$ & $18 / 78.59 \%$ & $11 / 68.53 \%$ & $25 / 90.27 \%$ \\
\hline $\begin{array}{l}\text { Radius of the used wires in coupled resonator coils } \\
\text { (Section 4.1.3)/PTE }\end{array}$ & $1.2 \mathrm{~mm} / 76.38 \%$ & $5 \mathrm{~mm} / 81.45 \%$ & $1.2 \mathrm{~mm} / 68.53 \%$ & $5 \mathrm{~mm} / 75.06 \%$ \\
\hline $\begin{array}{l}\text { Number of coupled resonator coils } \\
\text { (Section 4.1.4)/PTE }\end{array}$ & $3 / 76.38 \%$ & $11 / 90.27 \%$ & $4 / 68.53 \%$ & $7 / 90.81 \%$ \\
\hline Operating frequency (Section 4.1.5)/PTE & $530 \mathrm{kHz} / 76.38 \%$ & $521 \mathrm{kHz} / 76.74 \%$ & $530 \mathrm{kHz} / 68.53 \%$ & $466 \mathrm{kHz} / 81.34 \%$ \\
\hline Source and load impedance (Section 4.1.6)/PTE & $3.45 \Omega, 17 \Omega / 76.38 \%$ & $0 \Omega, 12.6 \Omega / 92.32 \%$ & $1.42 \Omega, 17 \Omega / 68.53 \%$ & $0 \Omega, 19.3 \Omega / 88.95 \%$ \\
\hline
\end{tabular}

(iv) A necessary attribute that characterizes efficient DCR configurations is the ability to operate when a multitude of distance spans and frequencies occur without the need of precise manual tuning in terms of source and load impedances. Similarly to the automatic frequency tuning [3], it is possible to design systems that are automatically adjusted in order to provide maximum PTEs as DCR configurations are expanded within the system's working range.

4.1.7. Discussion on Parameters That Affect PTE of DCR Configurations. The aforementioned analysis has identified the most important design parameters that influence PTE of practical DCR configurations. In Table 3, these parameters as well as their PTE performance are synopsized in the case of considered DCR configuration scenarios A and B when nominal values of Tables 1 and 2 and optimal values of Sections 4.1.1-4.1.6 are adopted.

Examining Table 3, it is clearly shown that DCR configuration parameters of scenario A are very well adjusted whereas scenario B ones are adequately tuned. Anyway, in all the cases examined, their PTEs are relatively close to the optimal values. Therefore, due to these favorable characteristics, these two DCR configurations can be efficiently used in the following theoretical analyses where practical DCR configurations are required to be installed.

Moreover, as it has already been identified and mentioned in [64], the agreement between the theoretical analysis and experimental data is excellent. This result shows that PTE of DCR configurations can be accurately predicted and optimized through the developed models without the need of further experimentation.

\subsection{Practical DCR Configurations and Approximate CSM} Method. Until now, the theoretical analysis presented in Sections 3.1-3.3 and its respective numerical results demonstrated in Sections 4.1.1-4.1.7 have accurately described PTE behavior of DCR configurations. However, the main problem of the theoretical analysis is the size of the used mutual inductance matrices that hinders its practical implementation when mid- and long-range practical DCR configurations are going to be deployed [40, 52, 60, 62-64]. To save computational resources and time, there is need of a model, such as the approximate CSM method, that gives quick and accurate numerical results for mid- and long-range DCR configurations.

Based on (16a)-(16c), in order to accurately apply the approximate CSM method, the following two-step procedure should be followed.

(1) Initialization Process. On the basis of (16b), the initialization process outlines the contribution of source and load modules to PTE. Having applied the theoretical analysis of Section 4.1.4 for $n=2$, $\mathrm{PTE}_{\text {approx }, 2}$ is assumed equal to the theoretical PTE.

(2) Coupled Resonator Contribution. During this phase, the contribution of coupled resonators to PTE is computed. On the basis of (16a), having applied the theoretical analysis of Section 4.1.4 for $n$ coupled resonators, $\mathrm{PTE}_{\mathrm{approx}, n}$ is assumed equal to the theoretical PTE. Since PTE approx, $2_{2}$ and $\mathrm{PTE}_{\text {approx }, n}$ are known, the additional PTE degradation due to the insertion of one new DCR module $\left|T_{i, 11}^{\prime}\right|^{-2}$ is straightforwardly computed from (16a).

The accuracy of the approximate CSM method is validated through the comparison of its numerical results with the respective ones of the theoretical analysis of Sections 3.13.3. Towards that direction, DCR configuration scenario A, whose properties are detailed in Tables 1 and 2, is only considered. Due to configuration and numerical result similarities with DCR configuration scenario A, DCR configuration scenario B is neglected, hereafter.

Across this paper, as it concerns DCR configuration scenario A properties, the number of coupled resonators and the distance span are redefined so that the accuracy of the approximate CSM method will be examined. Note that, in this subsection, the transfer distance of DCR configurations, which are based on DCR configuration scenario A properties, is variable and depends on the number of coupled resonators and the distance span through

$$
d=(n-1) \cdot d_{\mathrm{SPAN}}
$$

More specifically, in Figures 11(a) and 11(b), PTE is plotted versus the number of coupled resonators and distance 


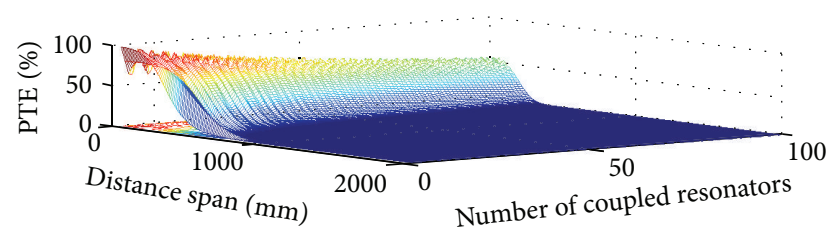

(a)

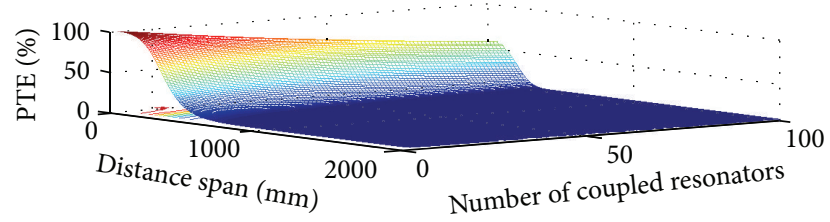

(b)

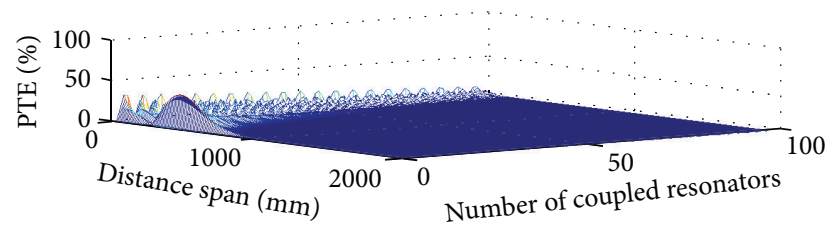

(c)

FIGURE 11: PTE versus the number of coupled resonators and distance span for practical DCR configurations. (a) Theoretical analysis. (b) Approximate CSM method. (c) Absolute difference between theoretical analysis and approximate CSM method.

span when the theoretical analysis of Sections 3.1-3.3 and the approximate CSM method is applied, respectively. In Figure 11(c), the absolute PTE difference between these two methodologies is drawn.

From Figures 11(a)-11(c), it is observed that the theoretical analysis and the approximate CSM method coincide when the number of coupled resonators and/or the distance span are large enough whereas they yield very close results in the case of small DCR configurations (i.e. few coupled resonators, small distance spans). Thus, the approximate CSM method describes PTE accurately either in depth or in extent in the mid- and long-range DCR configurations that are the configurations of interest.

In numerical terms, when practical DCR configurations are deployed, PTE ranges from $4.56 \times 10^{-15} \%$ to $98.33 \%$ and from $3.43 \times 10^{-15} \%$ to $97.67 \%$ in the case of theoretical analysis and approximate CSM method, respectively. Actually, in the $95 \%$ of the practical DCR configurations examined in Figures 11(a)-11(c), the absolute difference between these two methodologies is below $4.92 \%$. Thus, the approximate CSM method offers an accurate representation of the PTE while it is easily adapted to various DCR configurations. The approximate CSM method will be adopted in the rest of the simulations.

Finally, the huge set of available PTE values gives a lot of arrows in the quiver of DCR configuration designers letting a myriad of potential applications to be developed. Some applications among them that are related with power transmission and distribution are going to be highlighted in the following analysis.
4.3. Power Transformers and Practical DCR Configurations. Today's power grids need to become smarter so as to provide an affordable, reliable, and sustainable power supply [80]. Recently, considerable activity has been carried out in order to guide the development of future's smart power grids. However, the majority of these activities emphasizes only the construction, renewable sources and communications side leaving outside the frame state-of-the-art concepts such as WPT technology. This subsection highlights a new vision for the future's smart grids in which the replacement potential of $\mathrm{HV} / \mathrm{MV}, \mathrm{MV} / \mathrm{LV}$ and $\mathrm{HV} / \mathrm{LV}$ transformers (and part of their transmission line branches) is identified. In this vision, each power transformer can be regarded as a practical DCR configuration that functionally consists of a cascade of DCR modules with source voltage equal to power transformer input voltage. The features and functions of DCR configurations, as well as the fertile ground where these features and functions are enabled, are discussed in this subsection.

4.3.1. Overview of $H V, M V$, and LV Transmission Lines and Their Respective Power Transformers. As it has already been mentioned in Section 2.1, the power grid is mainly divided into three major functions (i.e., power generation, transmission, and distribution) that mainly support three (voltage level) subnetworks, namely [24, 25, 43, 62, 86, 87, 137-139], the following.

(1) HV Subnetwork. The ten most typical transmission lines of this subnetwork around the world are those of $1000 \mathrm{kV}, 765 \mathrm{kV}, 500 \mathrm{kV}, 400 \mathrm{kV}, 230 \mathrm{kV}, 220 \mathrm{kV}$, $132 \mathrm{kV}, 110 \mathrm{kV}, 66 \mathrm{kV}$, and $50 \mathrm{kV}$.

(2) MV Subnetwork. The ten most common types of transmission lines of this subnetwork around the world are those of $35 \mathrm{kV}, 33 \mathrm{kV}, 22 \mathrm{kV}, 15 \mathrm{kV}, 11 \mathrm{kV}$, $10 \mathrm{kV}, 6.6 \mathrm{kV}, 6 \mathrm{kV}, 3.3 \mathrm{kV}$, and $2.2 \mathrm{kV}$.

(3) LV Subnetwork. The three most typical transmission lines of this subnetwork around the world are those of $400 \mathrm{~V}, 380 \mathrm{~V}$, and $220 \mathrm{~V}$.

In accordance with Section 2.2 and taking under consideration the voltage levels of the above three subnetworks, three main categories of step-down transformers occur.

(i) $H V / M V$ and $M V / L V$ Power Transformers. HV/MV and MV/LV power transformers define the "voltage bridge" between their input-HV and $\mathrm{MV}$, respectively-and their output-MV and LV, respectively-subnetworks. Their TRs depend on these input and output subnetworks.

(ii) $H V / L V$ power transformers. Similarly to these two main categories and as it has already been mentioned in Section 2.2, in rare cases of power delivery, $\mathrm{HV} / \mathrm{LV}$ power transformers can be deployed constituting the third main category of step-down transformers.

Depending on their TRs, $10 \times 10=100 \mathrm{HV} / \mathrm{MV}, 10 \times$ $3=30 \mathrm{MV} / \mathrm{LV}$, and $10 \times 3=30 \mathrm{HV} / \mathrm{LV}$ power transformers are examined in the rest of this paper. Their input and output voltage levels as well as their respective TRs are reported in Table 4. 
TABLE 4: Operation characteristics of HV/MV, MV/LV, and HV/LV power transformers.

\begin{tabular}{|c|c|c|c|c|c|c|c|c|c|c|c|c|c|c|}
\hline IV & $\mathrm{V}$ & TR & IV & $\mathrm{V}$ & TR & IV & $\mathrm{OV}$ & TR & IV & DV & TR & IV & OV & TR \\
\hline \multicolumn{15}{|c|}{ HV/MV power transformers } \\
\hline $000 \mathrm{kV}$ & $35 \mathrm{kV}$ & $3.5 \%$ & $1000 \mathrm{kV}$ & $33 \mathrm{kV}$ & $3.3 \%$ & $1000 \mathrm{kV}$ & $22 \mathrm{kV}$ & $2.2 \%$ & $1000 \mathrm{kV}$ & V & $1.5 \%$ & $\mathrm{kV}$ & $1 \mathrm{kV}$ & $1.1 \%$ \\
\hline $1000 \mathrm{kV}$ & $10 \mathrm{kV}$ & $1 \%$ & 1000 & & $0.66 \%$ & 1000 & & $0.6 \%$ & & & $33 \%$ & & & $.22 \%$ \\
\hline $65 \mathrm{kV}$ & $35 \mathrm{kV}$ & $.58 \%$ & $765 \mathrm{kV}$ & $33 \mathrm{kV}$ & $4.31 \%$ & $765 \mathrm{kV}$ & $22 \mathrm{kV}$ & $2.88 \%$ & $765 \mathrm{kV}$ & $15 \mathrm{kV}$ & $1.96 \%$ & $765 \mathrm{kV}$ & $11 \mathrm{kV}$ & $1.44 \%$ \\
\hline $65 \mathrm{kV}$ & $10 \mathrm{kV}$ & $1.31 \%$ & $765 \mathrm{kV}$ & $6.6 \mathrm{kV}$ & $0.86 \%$ & & $6 \mathrm{kV}$ & $0.78 \%$ & & $3.3 \mathrm{kV}$ & $0.43 \%$ & & & $.29 \%$ \\
\hline $00 \mathrm{kV}$ & $35 \mathrm{kV}$ & $7 \%$ & $500 \mathrm{kV}$ & $33 \mathrm{kV}$ & $6.6 \%$ & $500 \mathrm{kV}$ & $22 \mathrm{kV}$ & $4.4 \%$ & $500 \mathrm{kV}$ & $15 \mathrm{kV}$ & $3 \%$ & & $11 \mathrm{kV}$ & $2.2 \%$ \\
\hline $500 \mathrm{kV}$ & $10 \mathrm{kV}$ & $2 \%$ & $500 \mathrm{kV}$ & $6.6 \mathrm{kV}$ & $1.32 \%$ & $500 \mathrm{kV}$ & $6 \mathrm{kV}$ & $1.2 \%$ & & $3.3 \mathrm{kV}$ & $0.66 \%$ & & & $0.44 \%$ \\
\hline $400 \mathrm{kV}$ & $35 \mathrm{kV}$ & $.75 \%$ & $400 \mathrm{kV}$ & $33 \mathrm{kV}$ & $8.25 \%$ & $400 \mathrm{kV}$ & $22 \mathrm{kV}$ & $5.5 \%$ & & $15 \mathrm{kV}$ & $.75 \%$ & $\mathrm{~V}$ & V & $2.75 \%$ \\
\hline $400 \mathrm{kV}$ & $10 \mathrm{kV}$ & $2.5 \%$ & 400 & $6.6 \mathrm{kV}$ & $1.65 \%$ & 400 & $6 \mathrm{kV}$ & $1.5 \%$ & & $3.3 \mathrm{kV}$ & $.83 \%$ & & & $0.55 \%$ \\
\hline $230 \mathrm{kV}$ & $35 \mathrm{kV}$ & $20 \%$ & & & & & 221 & & & & & & & \\
\hline $30 \mathrm{kV}$ & $10 \mathrm{kV}$ & 35 & 2 & $6.6 \mathrm{kV}$ & $2.87 \%$ & 230 & $6 \mathrm{k}$ & $2.61 \%$ & $\mathrm{~V}$ & $\mathrm{~V}$ & 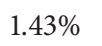 & & & $0.96 \%$ \\
\hline $20 \mathrm{kV}$ & $35 \mathrm{kV}$ & & & & & & & & & & & & & $5 \%$ \\
\hline $20 \mathrm{kV}$ & $10 \mathrm{kV}$ & 55 & $J$ & $6.6 \mathrm{kV}$ & $3 \%$ & $\mathrm{~V}$ & $6 \mathrm{kV}$ & 27 & $\mathrm{kV}$ & $\mathrm{V}$ & $15 \%$ & & & $1 \%$ \\
\hline $2 \mathrm{kV}$ & $35 \mathrm{kV}$ & $26.5 \%$ & & & & & & & & & & & & $33 \%$ \\
\hline $32 \mathrm{kV}$ & $10 \mathrm{kV}$ & $58 \%$ & & $6.6 \mathrm{kV}$ & $5 \%$ & & $6 \mathrm{kV}$ & 4.5 & & $\mathrm{~V}$ & 2. & & & $67 \%$ \\
\hline $0 \mathrm{kV}$ & $35 \mathrm{kV}$ & $8 \%$ & & & $30 \%$ & & 22 & $20 \%$ & & & $13.6 \%$ & & & $10 \%$ \\
\hline $0 \mathrm{kV}$ & $10 \mathrm{kV}$ & $9.09 \%$ & 110 & $6.6 \mathrm{kV}$ & $6 \%$ & 110 & $6 \mathrm{kV}$ & 5450 & & $\mathrm{kV}$ & 39 & & & $2 \%$ \\
\hline $66 \mathrm{kV}$ & $35 \mathrm{kV}$ & $53 \%$ & 66 & $\mathrm{kV}$ & $50 \%$ & & $22 \mathrm{kV}$ & 3. & & $15 \mathrm{kV}$ & $22.7 \%$ & & $1 \mathrm{kV}$ & $16.7 \%$ \\
\hline $66 \mathrm{kV}$ & $10 \mathrm{kV}$ & $15.2 \%$ & $66 \mathrm{kV}$ & $6.6 \mathrm{kV}$ & & & $6 \mathrm{kV}$ & & & $3.3 \mathrm{kV}$ & & $66 \mathrm{kV}$ & $2.2 \mathrm{kV}$ & $3.33 \%$ \\
\hline $0 \mathrm{kV}$ & $35 \mathrm{kV}$ & $70 \%$ & & $33 \mathrm{kV}$ & 6 & V & $22 \mathrm{kV}$ & 44 & & & & & & $22 \%$ \\
\hline $\mathrm{kV}$ & $10 \mathrm{kV}$ & 2 & & & & $50 \mathrm{kV}$ & $6 \mathrm{kV}$ & $12 \%$ & & & & & & $4 \%$ \\
\hline \multicolumn{15}{|c|}{ MV/LV power transformers } \\
\hline $5 \mathrm{kV}$ & $400 \mathrm{~V}$ & $4 \%$ & & $\mathrm{~V}$ & $1.09 \%$ & $35 \mathrm{kV}$ & $220 \mathrm{~V}$ & $0.63 \%$ & $\mathrm{~V}$ & & $1.21 \%$ & & & $15 \%$ \\
\hline $3 \mathrm{kV}$ & $220 \mathrm{~V}$ & $0.67 \%$ & $22 \mathrm{kV}$ & $400 \mathrm{~V}$ & $1.82 \%$ & & & & & & & & & $2.67 \%$ \\
\hline $\mathrm{kV}$ & $380 \mathrm{~V}$ & $2.53 \%$ & $15 \mathrm{kV}$ & $220 \mathrm{~V}$ & $1.47 \%$ & $\mathrm{~V}$ & 40 & $3.64 \%$ & $11 \mathrm{kV}$ & $\mathrm{V}$ & $3.45 \%$ & $\mathrm{~V}$ & V & $2 \%$ \\
\hline $0 \mathrm{kV}$ & $400 \mathrm{~V}$ & $4 \%$ & $10 \mathrm{kV}$ & $380 \mathrm{~V}$ & $3.8 \%$ & $10 \mathrm{kV}$ & $220 \mathrm{~V}$ & $2.2 \%$ & $6.6 \mathrm{kV}$ & $400 \mathrm{~V}$ & $6.06 \%$ & & & $5.76 \%$ \\
\hline $6.6 \mathrm{kV}$ & $220 \mathrm{~V}$ & $3.33 \%$ & $6 \mathrm{kV}$ & $400 \mathrm{~V}$ & $6.67 \%$ & $6 \mathrm{kV}$ & $380 \mathrm{~V}$ & $6.33 \%$ & $6 \mathrm{kV}$ & $220 \mathrm{~V}$ & $3.67 \%$ & & $400 \mathrm{~V}$ & $12.1 \%$ \\
\hline $3.3 \mathrm{kV}$ & $380 \mathrm{~V}$ & $11.5 \%$ & $3.3 \mathrm{kV}$ & $220 \mathrm{~V}$ & 6670 & $2.2 \mathrm{kV}$ & $400 \mathrm{~V}$ & $18.2 \%$ & & & & & & $10 \%$ \\
\hline \multicolumn{15}{|c|}{ HV/LV power transformers } \\
\hline $00 \mathrm{kV}$ & $400 \mathrm{~V}$ & 170 & & & & & $220 \mathrm{~V}$ & & & & & & & (2) \\
\hline $765 \mathrm{kV}$ & $220 \mathrm{~V}$ & $0.03 \%$ & & & & & & & & & & & & $0.1 \%$ \\
\hline $400 \mathrm{kV}$ & $380 \mathrm{~V}$ & $0.1 \%$ & $400 \mathrm{kV}$ & $220 \mathrm{~V}$ & $0.06 \%$ & $230 \mathrm{kV}$ & $400 \mathrm{~V}$ & $0.17 \%$ & $230 \mathrm{kV}$ & $380 \mathrm{~V}$ & $0.17 \%$ & $230 \mathrm{kV}$ & $220 \mathrm{~V}$ & $0.1 \%$ \\
\hline $220 \mathrm{kV}$ & $400 \mathrm{~V}$ & $0.18 \%$ & $220 \mathrm{kV}$ & $380 \mathrm{~V}$ & $0.17 \%$ & $220 \mathrm{kV}$ & $220 \mathrm{~V}$ & $0.1 \%$ & $132 \mathrm{kV}$ & $400 \mathrm{~V}$ & $0.30 \%$ & $132 \mathrm{kV}$ & $380 \mathrm{~V}$ & $0.29 \%$ \\
\hline $132 \mathrm{kV}$ & $220 \mathrm{~V}$ & $0.17 \%$ & $110 \mathrm{kV}$ & $400 \mathrm{~V}$ & $0.36 \%$ & $110 \mathrm{kV}$ & $380 \mathrm{~V}$ & $0.35 \%$ & $110 \mathrm{kV}$ & $220 \mathrm{~V}$ & $0.2 \%$ & $66 \mathrm{kV}$ & $400 \mathrm{~V}$ & $0.61 \%$ \\
\hline $66 \mathrm{kV}$ & $380 \mathrm{~V}$ & $0.58 \%$ & $66 \mathrm{kV}$ & $220 \mathrm{~V}$ & $0.33 \%$ & $50 \mathrm{kV}$ & $400 \mathrm{~V}$ & $0.8 \%$ & $50 \mathrm{kV}$ & $380 \mathrm{~V}$ & $0.76 \%$ & $50 \mathrm{kV}$ & $220 \mathrm{~V}$ & $0.44 \%$ \\
\hline
\end{tabular}

Input voltage level: IV. Output voltage level: OV.

4.3.2. The Potential of Replacing $H V / M V, M V / L V$, and $H V / L V$ Transformers with Practical DCR Configurations. Already mentioned in the literature $[52,64]$, a DCR configuration can be interpreted as an expansion of a power transformer, which consists of two coils. Actually, the equations of a power transformer are well-established in textbooks [76-78]. To promote the analysis, from (12), it is reminded that PTE can approximately be assumed equal to the square of the absolute value of its TR for a given power transformer.

Thus, studying Table 4 , it is observed that the TR of power transformers ranges from $0.02 \%$ to $70 \%$. However, from Section 4.2, it has been validated that practical DCR configuration PTE ranges from $3.43 \times 10^{-15} \%$ to $97.67 \%$. This implies that practical DCR configuration TR approximately ranges from $5.86 \times 10^{-9} \%$ to $98.83 \%$. Therefore, practical DCR configuration TR set defines a superset that includes the respective TR set of power transformers. In order to validate this important finding, in Figure 12(a), practical DCR configuration TR is plotted versus the number of coupled resonators and transfer distance when DCR configuration scenario A properties are adopted. In Figures 12(b) and 12(c), the minimum and maximum power transformer TR contour lines are curved, respectively.

From Figures 12(a)-12(c), it is evident that practical DCR configurations can affordably, reliably, and sustainably replace either HV/MV or MV/LV, or HV/LV power transformers during all their operation cycle since TR of practical DCR configurations overlaps the respective one of power transformers. However, WPT technology defines a new technology solution that demands its time and a lot of research efforts so as to become mature and efficient to substitute already well validated technologies such as power transformer one.

Furthermore, the numerical results of Figures 12(a)-12(c) demonstrate that efficient transfer paths of practical DCR configurations can be long enough reaching distances more 


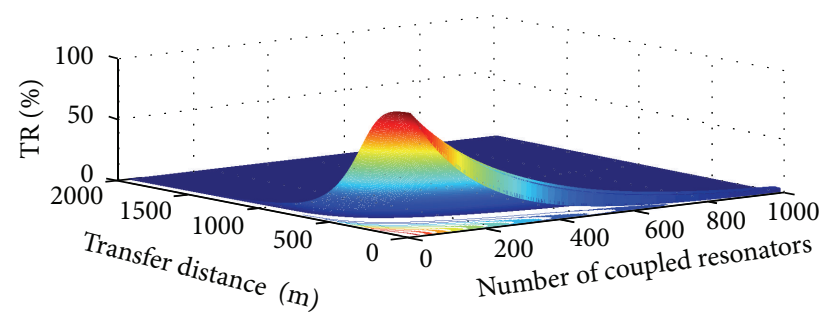

(a)

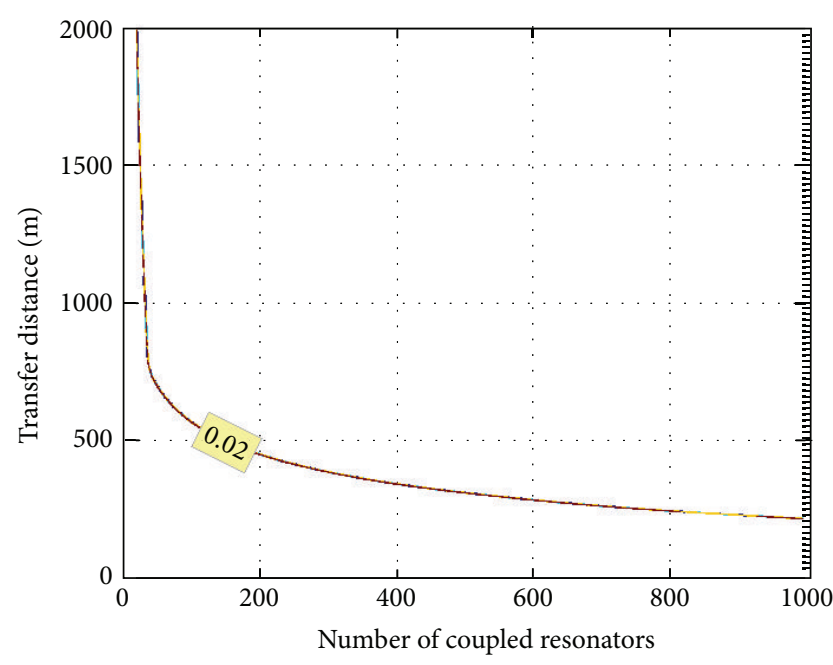

(b)

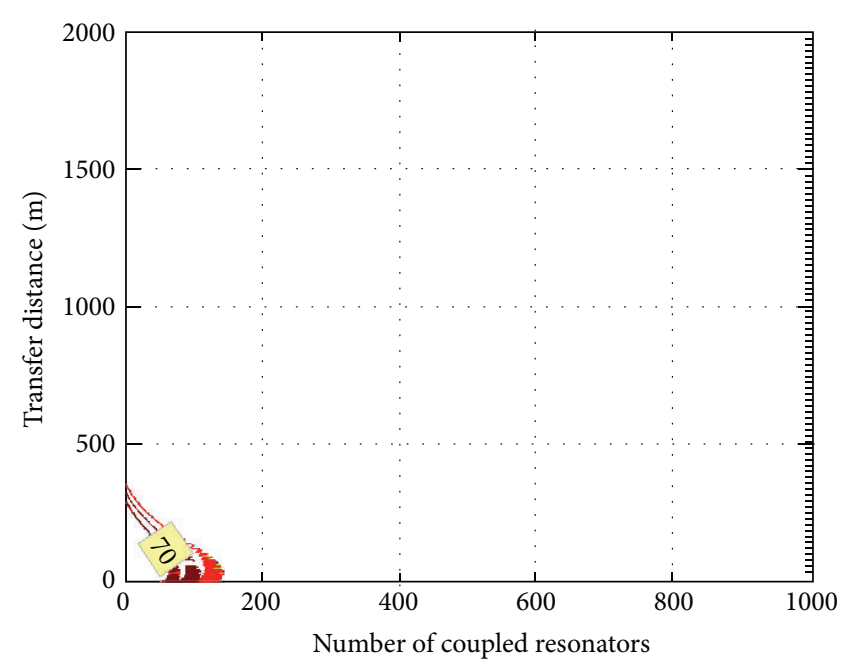

(c)

FIGURE 12: TR versus the number of coupled resonators and transfer distance. (a) Practical DCR configurations. (b) Minimum power transformer TR contour lines. (c) Maximum power transformer TR contour lines.

than $1 \mathrm{~km}$ by using only few coupled resonators. This order of distances does not only render acceptable the substitution of power transformers but can also permit the replacement of entire transmission line branches. Anyway, plots such as those of Figure 12(a) can operate as rule of thumb in order to design practical DCR configurations given the desired transfer distance and TR.

4.4. Last Cable Problem, Power Transformers, and Practical DCR Configurations. Nowadays, interest in the research and development of WPT technology has skyrocketed. The primary objective of a possible widespread adoption of WPT systems is the solution of last cable problem. To solve this problem, WPT networks can be mixed with the traditional power grid infrastructure. Anyway, last mile and last cable problems as well as their integration open new horizons in the sciences of electrical engineering and sociology.

Prior to investigate the capabilities of practical DCR configurations in terms of minimum and maximum supported WPT distances and emphasize the last cable problem solution, an overview of the parameters that define this problem is given: the lengths of transmission line branches and the dimensions of power transformers.

4.4.1. Exploring the Parameters of Last Cable Problem: Lengths of Transmission Line Branches and Dimensions of Power Transformers. On the basis of the subnetwork taxonomy of
Section 4.3.1, the characteristics of the respective transmission lines are the following $[24,25,43,62,86,87,137-146]$.

(1) HV Subnetwork. Overhead HV transmission lines generally define the lowest cost delivery method for large bulks of electric power. Utilities mainly employ overhead HV subnetwork for new urban, suburban, and rural installations. Today, thousands of $\mathrm{km}$ of overhead HV transmission lines are installed in more than 120 countries. In general, they stretch from approximately $25 \mathrm{~km}$ to $190 \mathrm{~km}$ from the generation points before reaching critical load destinations. Shorter branches in the range of $10 \mathrm{~km}$ to $50 \mathrm{~km}$ are used in order to connect overhead HV transmission lines either between them or with HV/MV transformers.

(2) MV and LV Subnetwork. Utilities employ either the overhead or the underground distribution power grid for their new urban, suburban, and rural MV and LV installations. Their choice depends on different criteria such as cost requirements, existing grid topology, and plan constraints. Today, in urban areas, about $45 \%-75 \%$ of the underground transmission lines (either MV or LV ones, either main or branch ones) exhibit path lengths shorter than $200 \mathrm{~m}$. Only 1\%-9\% of them present lengths longer than $500 \mathrm{~m}$. These path 
lengths are quite shorter compared to the overhead transmission where path lengths up to $1000 \mathrm{~m}$ may be encountered. Actually, in suburban and rural environments, these lengths are significantly longer.

As it regards power transformers, their dimensions are determined by the input voltage, the output voltage, and the supported capacity rating. Among these three factors, the capacity rating often is the key parameter rather than input and output voltages. Based on the aforementioned subnetwork classification, the typical dimensions of the used power transformers are the following [141, 145-147].

(1) $H V / M V$ and $H V / L V$ Power Transformers. Due to their high capacity rating and high input voltage, their dimensions are significantly greater than the respective ones of MV/LV transformers. Their typical length, width and height range from $2650 \mathrm{~mm}$ to $4400 \mathrm{~mm}$, from $2250 \mathrm{~mm}$ to $4250 \mathrm{~mm}$ and from $2750 \mathrm{~mm}$ to $4900 \mathrm{~mm}$, respectively.

(2) $M V / L V$ Power Transformers. Except for the various types of transmission lines, MV/LV power transformers define the most common component of today's power grid. There are different types of MV/LV transformers depending on the use. Their typical length, width and height range from $670 \mathrm{~mm}$ to $2400 \mathrm{~mm}$, from $600 \mathrm{~mm}$ to $1450 \mathrm{~mm}$ and from $885 \mathrm{~mm}$ to $2585 \mathrm{~mm}$, respectively.

4.4.2. Approaching the Solution of Last Cable Problem. WPT through DCR configurations can be categorized into two application classes, namely, as follows.

(i) Short- and Mid-Range Application Class. To date, this class has high promises as an equipment replacement technology and seems to be particularly suitable for daily and/or urban applications. In fact, the interactions of short- and mid-range DCR configurations with external resonators are reduced due to their simple DCR configuration structure $[44,54,103,122$, 148]. In order to deliver enhanced power delivery services in short- and mid-range application class, few coupled resonators and/or small distance spans are required.

(ii) Long-Range Application Class. This class presents limited implementation potential for consumer applications and urban environments due to the high transferred power and long DCR configurations that are necessary to achieve the levels of power comparable to a power transformer. In order to deliver enhanced power delivery services in longrange applications, several coupled resonators and relatively larger distance spans in comparison with the short- and mid-range application class are required from the installed DCR configurations. Through this class and depending on the subnetwork, DCR configurations can replace both power grid equipment and part of its transmission line branches. In that sense, suburban and rural areas define the most
TABLE 5: Minimum, median, and maximum TR of HV/MV, MV/LV, and $\mathrm{HV} / \mathrm{LV}$ power transformers.

\begin{tabular}{|c|c|c|c|c|c|c|c|c|}
\hline \multicolumn{3}{|c|}{ Minimum } & \multicolumn{3}{|c|}{ Median } & \multicolumn{3}{|c|}{ Maximum } \\
\hline IV & $\mathrm{OV}$ & $\mathrm{TR}$ & IV & $\mathrm{OV}$ & TR & IV & $\mathrm{OV}$ & TR \\
\hline \multicolumn{9}{|c|}{ HV/MV power transformers } \\
\hline $1000 \mathrm{kV}$ & $2.2 \mathrm{kV}$ & $0.22 \%$ & $220 \mathrm{kV}$ & $10 \mathrm{kV}$ & $4.55 \%$ & $50 \mathrm{kV}$ & $35 \mathrm{kV}$ & $70 \%$ \\
\hline \multicolumn{9}{|c|}{ MV/LV power transformers } \\
\hline $35 \mathrm{kV}$ & $220 \mathrm{~V}$ & $0.63 \%$ & $6.6 \mathrm{kV}$ & $220 \mathrm{~V}$ & $3.33 \%$ & $2.2 \mathrm{kV}$ & $400 \mathrm{~V}$ & $18.2 \%$ \\
\hline \multicolumn{9}{|c|}{$\mathrm{HV} / \mathrm{LV}$ power transformers } \\
\hline $00 \mathrm{kV}$ & $20 \mathrm{~V}$ & 0.02 & $230 \mathrm{k}$ & 400 & 0.17 & $50 \mathrm{kV}$ & $400 \mathrm{~V}$ & 0.8 \\
\hline
\end{tabular}

Input voltage level: IV. Output voltage level: OV.

appropriate installation environments, where longrange application class can be applied across.

To investigate the applicability of mid- and long-range application classes and, hence, their contribution to the solution of last cable problem, $\mathrm{HV} / \mathrm{MV}, \mathrm{MV} / \mathrm{LV}$, and HV/LV power transformers are treated separately in the following simulation results. On the basis of Table 4, the minimum, the median and the maximum TR values of $\mathrm{HV} / \mathrm{MV}, \mathrm{MV} / \mathrm{LV}$, and $\mathrm{HV} / \mathrm{LV}$ power transformers are reported in Table 5. In the same Table, the corresponding input and output voltage levels are also reported.

In Figure 13(a), the transfer distance is plotted versus the number of coupled resonators given the minimum TR of $\mathrm{HV} / \mathrm{MV}$ power transformers when DCR configuration scenario A properties are adopted. In the same Figure, with respect to Section 4.4.1, the minimum and maximum dimensions of $\mathrm{HV} / \mathrm{MV}$ transformers are also given. In Figures 13(b) and 13(c), same curves with Figure 13(a) are drawn but for the median and maximum TR, respectively. In Figures 14(a)14(c) and 15(a)-15(c), same plots with Figures 13(a)-13(c) are curved in the case of $\mathrm{MV} / \mathrm{LV}$ and $\mathrm{HV} / \mathrm{LV}$ transformers, respectively.

Observing Figures 13(a)-13(c), 14(a)-14(c), and 15(a)15(c), several interesting conclusions regarding the interaction between WPT technology and last cable problem can be deduced, more specifically as follows.

(1) Depending on the required TR, there is a plethora of available DCR configurations and corresponding transfer distances. Given the TR and the desired transfer distance, the exact number of coupled resonators can straightforwardly be determined for all the types of today's step-down power transformers.

(2) In general, transfer distance of DCR configurations is a concave function with respect to the number of their coupled resonators for a given TR. Combined with the knowledge of Figure 6, this concave behavior implies that the same transfer distance result can be achieved through two different DCR configurations in the majority of the transfer distance cases. This finding is very useful since the suitable selection among DCR configurations may differentiate depending on frequency and EMI constraints that are imposed by the authorities, the safety operation limitations with 


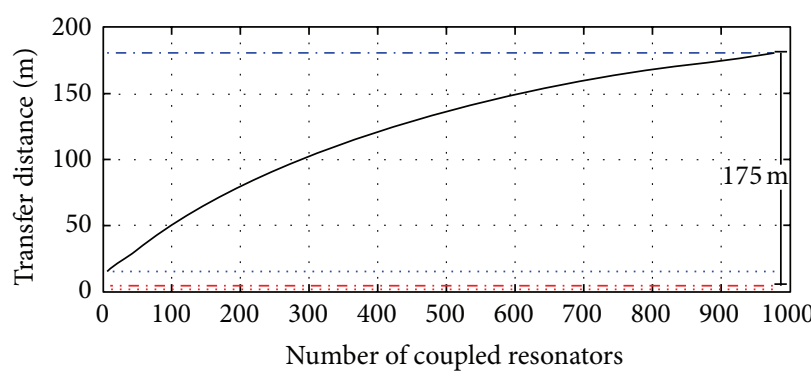

(a)

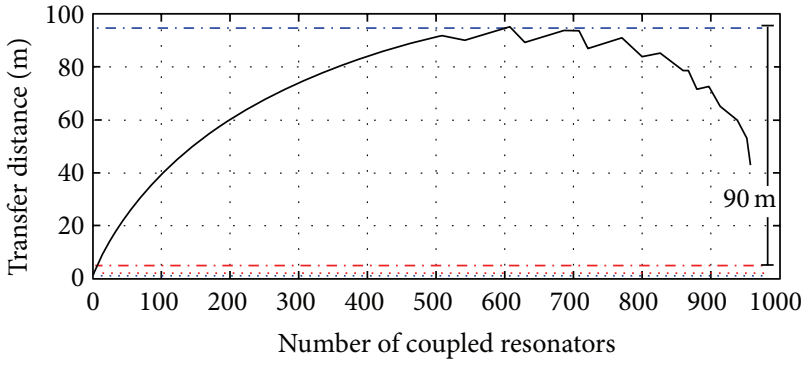

(b)

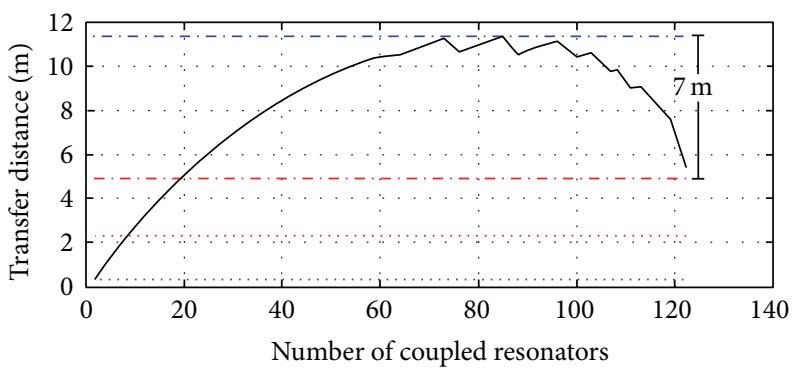

(c)

FIGURE 13: Transfer distance versus the number of coupled resonators when DCR configuration scenario A properties (-) are applied for various TRs as well as the minimum ( $\cdots$ ) and maximum (-.-) dimensions of HV/MV power transformers. (a) Minimum HV/MV power transformer TR. (b) Median HV/MV power transformer TR. (c) Maximum HV/MV power transformer TR.

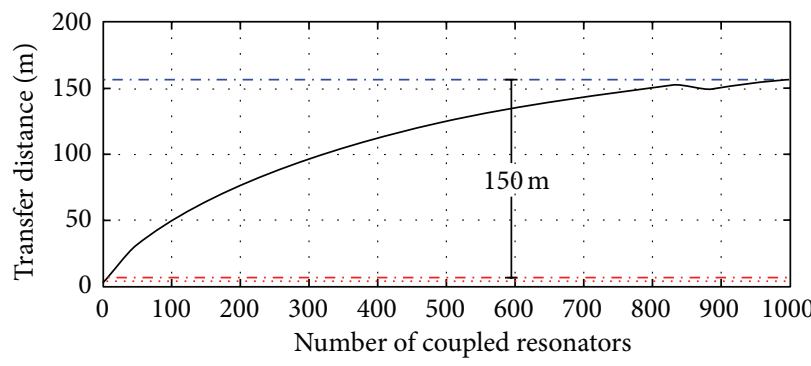

(a)

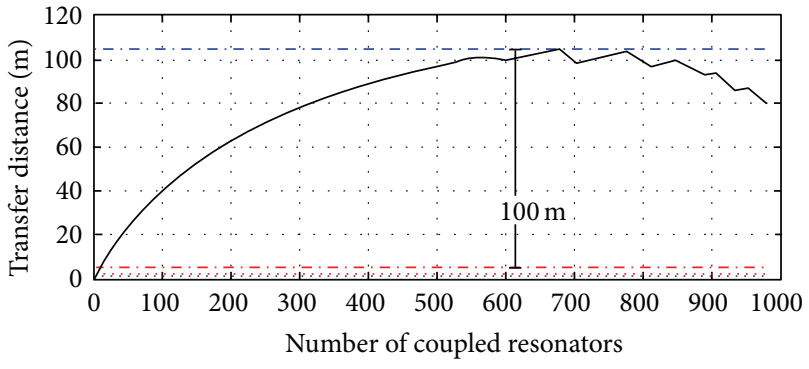

(b)

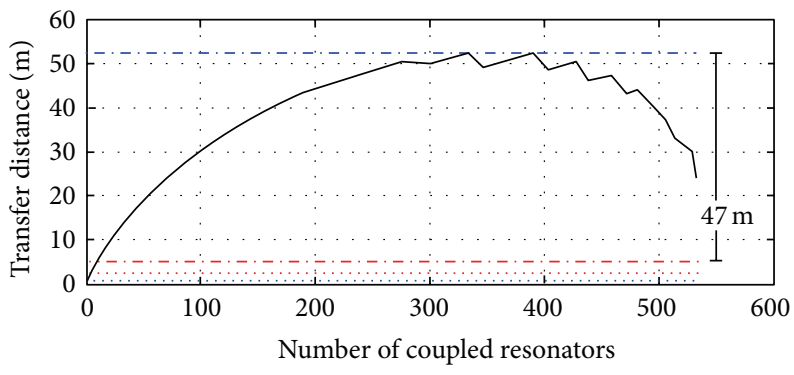

(c)

FIGURE 14: Same as Figure 13 but for MV/LV power transformers.

respect to the human presence and health, other application constraints, and so forth.

(3) The transfer distance range primarily depends on the required TR. Lower TRs-for example, HV/MV and $\mathrm{HV} / \mathrm{LV}$ power transformers-permit longer maximum DCR configuration transfer distances whereas higher TRs-for example, MV/LV power transformers-demand shorter ones. The same results apply in the case of minimum transfer distances.

(4) In all the cases examined, the dimensions of power transformers define small subsets of the corresponding DCR configuration transfer distance sets. Therefore, all the types of today's step-down power 


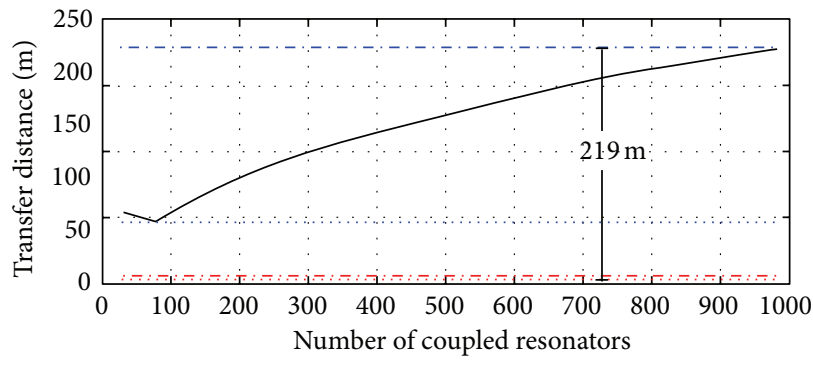

(a)

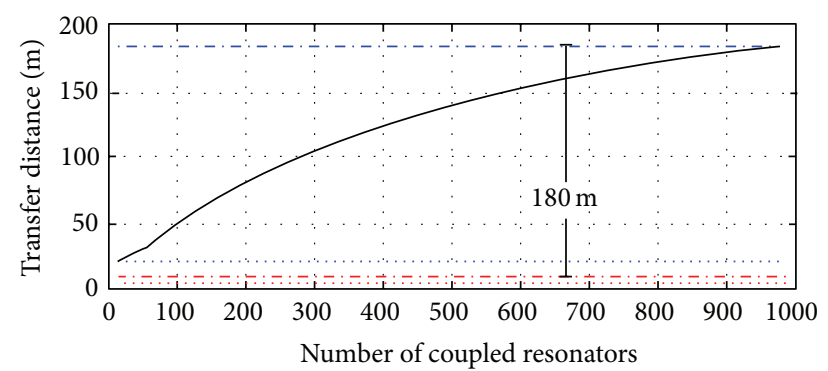

(b)

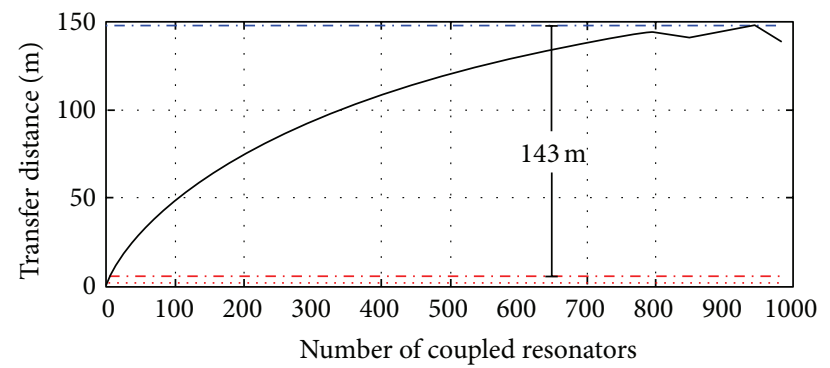

(c)

Figure 15: Same as Figure 13 but for HV/LV power transformers.

transformers can potentially be replaced by deploying a little number of coupled resonators without, however, exceeding their existing dimensions; say, $\mathrm{HV} / \mathrm{MV}, \mathrm{MV} / \mathrm{LV}$ and HV/LV transformers can be replaced with 4-20, 2-11 and 2-6 coupled resonators when DCR configuration scenario A properties are adopted.

(5) Despite the great potential of power transformer replacement, DCR configurations can straightforwardly help towards a partial solution of last cable problem. In fact, in all the cases examined, power transformer maximum dimensions are significantly lower than the maximum transfer distance supported by DCR configurations. On average, this difference between these two maxima is equal to $90 \mathrm{~m}, 100 \mathrm{~m}$ and $180 \mathrm{~m}$ in the case of $\mathrm{HV} / \mathrm{MV}, \mathrm{MV} / \mathrm{LV}$, and $\mathrm{HV} / \mathrm{LV}$ power transformers, respectively. Therefore, except for power transformers, DCR configurations can effectively replace part of their existing branch wiring.

(6) Combining the previous findings with the reports of Section 4.4.1, it is obvious that practical DCR configurations can replace entire transmission line branches in the case of MV and LV subnetworks whereas they can substitute parts of HV subnetwork transmission line branches. In numerical terms and on average, this difference between these two maxima can range from $7 \mathrm{~m}$ to $175 \mathrm{~m}$, from $47 \mathrm{~m}$ to $150 \mathrm{~m}$ and from $143 \mathrm{~m}$ to $219 \mathrm{~m}$ in the case of $\mathrm{HV} / \mathrm{MV}, \mathrm{MV} / \mathrm{LV}$ and $\mathrm{HV} / \mathrm{LV}$ power transformers, respectively, so that their surrounding transmission line branches can be replaced. Thus, the wiring replacement potential depends on the TR target, the dimensions of the transformer, and the transmission line branch lengths.

(7) According to Section 4.1.7 and Table 3, DCR configuration parameters of scenario A are very well adjusted and, thus, its PTE and TR performance gives a representative image of the capabilities of today's WPT technology in mid- and long-range applications. However, there is enough room for improvements so that DCR configurations will be perfectly tuned and, finally, reveal their optimum capabilities concerning last cable problem solution.

\section{Future Work}

In reality, there is a long journey ahead for WPT technology and its state-of-the-art products to be affordably, widely, reliably, sustainably, and safely adopted in the society, replacing some of the traditional and well-proven wired systems. However, during these preliminary stages of WPT technology development, theoretical aspects and advancements, visions and proofs of concept are welcome and necessary, as well.

DCR configurations will accelerate practical adaptations of WPT technology in various sectors of daily activity such as power delivery, industry, medicine, transportation and consumer electronics [60, 149]. Especially, in environments where sparking and arching hazards may occur, DCR configurations can be the perfect solution and adopted so as to eliminate any external metallic contacts [67].

Finally, the need for power electronics that have greater compactness, better manufacturability and higher performance triggers the pursuit of dramatic increases in operating frequencies of DCR configurations. Realizing advantages 
such as miniaturization, more sophisticated power applications, improved PTE and TR performance, and better integration of the passive components of DCR configurations, however, requires devices, passive components and circuit designs that can operate efficiently at the necessary frequencies $[150,151]$. Therefore, a series of interconnected and peripheral systems (e.g., rectifiers, cooling systems, source transistors, impedance matching systems, modulators, filters, input and output subsystems, e.t.c.) is required to be redesigned so that the operation optimization of practical DCR configurations will be ensured and, at the same time, the EMI of practical DCR configurations to the other already existing power and telecommunications systems will be reduced $[3,152]$.

\section{Conclusions}

In this paper, the replacement potential of step-down power transformers and their transmission line branches with DCR configurations has thoroughly been investigated.

Based on an exhaustive theoretical analysis as well as experimental and numerical assessment procedure, the important replacement potential of step-down power transformers with DCR configurations has been identified. Except for this critical verification, a significant number of secondary findings has been reported: first, the analytical theoretical analysis suitable for the study of DCR configurations has been presented and verified through numerical results and experimental measurements. In addition, it has been demonstrated that practical DCR configurations that have been used during numerical results and for power transformer replacements are well tuned concerning their PTE and TR performance in comparison with maximum achievable PTE and TR, respectively. Second, a great number of parameters that influences PTE and TR performance of DCR configurations has been recognized, namely, the radius of coupled resonator coils, the number of turns of coupled resonator coils, the radius of the used wires in coupled resonator coils, the number of coupled resonator coils, the operating frequency, and the source and load impedances. On the basis of these design parameters and the theoretical analysis outcomes, possible DCR configuration adjustments have been recognized so that the maximization of PTE and TR can occur. Third, the approximate CSM method has been proposed, applied and compared with the respective results of the theoretical analysis giving impressive converging results: in the $95 \%$ of the practical DCR configurations examined, the absolute TR difference between these two methodologies is below $4.92 \%$. The main benefit of approximate CSM method is its computational speed in comparison with the respective one of the theoretical analysis when mid- and long-range DCR configurations are deployed. Fourth, in all 160 cases of HV/MV, MV/LV, and $\mathrm{HV} / \mathrm{LV}$ power transformers used across the world, practical DCR configurations can comfortably replace all of them. Actually, $\mathrm{HV} / \mathrm{MV}, \mathrm{MV} / \mathrm{LV}$, and $\mathrm{HV} / \mathrm{LV}$ power transformers can be replaced with 4-20, 2-11 and 2-6 coupled resonators when practical DCR configurations are deployed regardless of their power transformer TRs. Fifth, taking into account a thorough report concerning dimensions of transformers and transmission line branches, it has been verified that practical DCR configurations cannot only substitute all stepdown power transformers of the today's power grid but can also replace entire transmission line branches too: in the case of $\mathrm{HV} / \mathrm{MV}, \mathrm{MV} / \mathrm{LV}$ and $\mathrm{HV} / \mathrm{LV}$ power transformers, DCR configurations can effectively replace $90 \mathrm{~m}, 100 \mathrm{~m}$, and $180 \mathrm{~m}$ of their existing transmission line wiring, respectively.

Finally, WPT technology and DCR configurations have been proven to be theoretically feasible technological solutions for replacing power transformers and their corresponding wiring. However, in order to become affordable, wide, reliable, sustainable, and safe power grid components, WPT technology and DCR configurations require a lot of academic research, system interaction and business interest in the related research topics.

\section{References}

[1] N. Tesla, "Apparatus for transmitting electrical energy," US patent number 1,119,732, December 1914.

[2] D. Kurschner, C. Rathge, and U. Jumar, "Design methodology for high efficient inductive power transfer systems with high coil positioning flexibility," IEEE Transactions on Industrial Electronics, vol. 60, no. 1, pp. 372-381, 2013.

[3] A. P. Sample, D. A. Meyer, and J. R. Smith, "Analysis, experimental results, and range adaptation of magnetically coupled resonators for wireless power transfer," IEEE Transactions on Industrial Electronics, vol. 58, no. 2, pp. 544-554, 2011.

[4] A. K. RamRakhyani, S. Mirabbasi, and M. Chiao, "Design and optimization of resonance-based efficient wireless power delivery systems for biomedical implants," IEEE Transactions on Biomedical Circuits and Systems, vol. 5, no. 1, pp. 48-63, 2011.

[5] G. A. Kendir, W. Liu, G. Wang et al., "An optimal design methodology for inductive power link with Class-E amplifier," IEEE Transactions on Circuits and Systems I, vol. 52, no. 5, pp. 857-866, 2005.

[6] S. C. Tang, F. A. Jolesz, and G. T. Clement, "A wireless batteryless deep-seated implantable ultrasonic pulser-receiver powered by magnetic coupling," IEEE Transactions on Ultrasonics, Ferroelectrics, and Frequency Control, vol. 58, no. 6, pp.1211-1221, 2011.

[7] M. P. Theodoridis and S. V. Mollov, "Distant energy transfer for artificial human implants," IEEE Transactions on Biomedical Engineering, vol. 52, no. 11, pp. 1931-1938, 2005.

[8] K. Shiba, A. Morimasa, and H. Hirano, "Design and development of low-loss transformer for powering small implantable medical devices," IEEE Transactions on Biomedical Circuits and Systems, vol. 4, no. 2, pp. 77-85, 2010.

[9] M. Sawan, S. Hashemi, M. Sehil, F. Awwad, M. Hajj-Hassan, and A. Khouas, "Multicoils-based inductive links dedicated to power up implantable medical devices: modeling, design and experimental results," Biomedical Microdevices, vol. 11, no. 5, pp. 1059-1070, 2009.

[10] M. Soma, D. C. Galbraith, and R. L. White, "Radio-frequency coils in implantable devices: misalignment analysis and design procedure," IEEE Transactions on Biomedical Engineering, vol. 34, no. 4, pp. 276-282, 1987.

[11] M. Kiani and M. Ghovanloo, "An RFID-based closed-loop wireless power transmission system for biomedical applications," IEEE Transactions on Circuits and Systems II, vol. 57, no. 4, pp. 260-264, 2010. 
[12] H. Vazquez-Leal, A. Gallardo-Del-Angel, R. Castaneda-Sheissa, and F. J. Gonzalez-Martinez, "The phenomenon of wireless energy transfer: experiments and philosophy," in Wireless Energy Transfer Based on Electromagnetic Resonance: Principles and Engineering Explorations, K. Y. Kim, Ed., pp. 978-953, InTech, 2012.

[13] F. Segura-Quijano, J. Garcia-Canton, J. Sacristan, T. Oses, and A. Baldi, "Wireless powering of single-chip systems with integrated coil and external wire-loop resonator," Applied Physics Letters, vol. 92, no. 7, Article ID 074102, 3 pages, 2008.

[14] N. A. Keeling, G. A. Covic, and J. T. Boys, "A unity-power-factor IPT pickup for high-power applications," IEEE Transactions on Industrial Electronics, vol. 57, no. 2, pp. 744-751, 2010.

[15] M. Dockhorn, D. Kürschner, and R. Mecke, "Contactless power transmission with new secondary converter topology," in Proceedings of the 13th International Power Electronics and Motion Control Conference (EPE-PEMC '08), pp. 1734-1739, September 2008.

[16] M. L. G. Kissin, J. T. Boys, and G. A. Covic, "Interphase mutual inductance in polyphase inductive power transfer systems," IEEE Transactions on Industrial Electronics, vol. 56, no. 7, pp. 2393-2400, 2009.

[17] J. De Boeij, E. Lomonova, J. L. Duarte, and A. J. A. Vandenput, "Contactless planar actuator with manipulator," in Proceedings of the European Conference on Power Electronics and Applications (EPE '07), pp. 1-9, Aalborg, Denmark, September 2007.

[18] D. Kürschner and C. Rathge, "Contactless energy transmission systems with improved coil positioning flexibility for high power applications," in Proceedings of the 39th IEEE Annual Power Electronics Specialists Conference (PESC '08), pp. 43264332, Rhodes, Greece, June 2008.

[19] U. K. Madawala and D. J. Thrimawithana, "A bidirectional inductive power interface for electric vehicles in V2G systems," IEEE Transactions on Industrial Electronics, vol. 58, no. 10, pp. 4789-4796, 2011.

[20] C.-S. Wang, O. H. Stielau, and G. A. Covic, "Design considerations for a contactless electric vehicle battery charger," IEEE Transactions on Industrial Electronics, vol. 52, no. 5, pp. 13081314, 2005.

[21] H. H. Wu, G. A. Covic, J. T. Boys, and D. J. Robertson, “A seriestuned inductive-power-transfer pickup with a controllable ACvoltage output," IEEE Transactions on Power Electronics, vol. 26, no. 1, pp. 98-109, 2011.

[22] Z. Pantic, S. Bhattacharya, and S. Lukic, "Optimal resonant tank design considerations for primary track compensation in inductive power transfer systems," in Proceedings of the 2nd IEEE Energy Conversion Congress and Exposition (ECCE '10), pp. 1602-1609, September 2010.

[23] A. P. Hu, C. Liu, and H. L. Li, "A novel contactless battery charging system for soccer playing robot," in Proceedings of the 15th International Conference on Mechatronics and Machine Vision in Practice (M2VIP '08), pp. 646-650, December 2008.

[24] M. Koizumi, K. Komurasaki, T. Komaru, Y. Mizuno, T. Shibata, and K. Kano, "Mid-range wireless power transmission in space," in Proceedings of the 8th Annual International Energy Conversion Engineering Conference, Nashville, Tenn, USA, July 2010.

[25] M. Koizumi, K. Komurasaki, Y. Mizuno, and Y. Arakawa, "Wireless power feeding with strongly coupled magnetic resonance for a flying object," Wireless Engineering and Technology, no. 2, pp. 86-89, 2012.

[26] T. Komaru, M. Koizumi, K. Komurasaki, T. Shibata, and K. Kano, "Compact and tunable transmitter and receiver for magnetic resonance power transmission to mobile objects," in Wireless Power Transfer-Principles and Engineering Explorations, K. Y. Kim, Ed., InTech, 2012.

[27] R. J. Sedwick, "Long range inductive power transfer with superconducting oscillators," Annals of Physics, vol. 325, no. 2, pp. 287-299, 2010.

[28] Y. Jang and M. M. Jovanović, "A contactless electrical energy transmission system for portable-telephone battery chargers," IEEE Transactions on Industrial Electronics, vol. 50, no. 3, pp. 520-527, 2003.

[29] C.-G. Kim, D.-H. Seo, J.-S. You, J.-H. Park, and B. H. Cho, "Design of a contactless battery charger for cellular phone," IEEE Transactions on Industrial Electronics, vol. 48, no. 6, pp. 1238-1247, 2001.

[30] J. Hirai, T.-W. Kim, and A. Kawamura, "Study on intelligent battery charging using inductive transmission of power and information," IEEE Transactions on Power Electronics, vol. 15, no. 2, pp. 335-345, 2000.

[31] D. Ahn and S. Hong, "Effect of coupling between multiple transmitters or multiple receivers on wireless power transfer," IEEE Transactions on Industrial Electronics, vol. 60, no. 7, pp. 2602-2613, 2013.

[32] H. Jabbar, Y. S. Song, and T. T. Jeong, "RF energy harvesting system and circuits for charging of mobile devices," IEEE Transactions on Consumer Electronics, vol. 56, no. 1, pp. 247-253, 2010.

[33] B. Choi, J. Nho, H. Cha, T. Ahn, and S. Choi, "Design and implementation of low-profile contactless battery charger using planar printed circuit board windings as energy transfer device," IEEE Transactions on Industrial Electronics, vol. 51, no. 1, pp. 140-147, 2004.

[34] J. Murakami, F. Sato, T. Watanabe et al., "Consideration on cordless power station-contactless power transmission system," IEEE Transactions on Magnetics, vol. 32, no. 5, pp. 50375039, 1996.

[35] K. Hatanaka, F. Sato, H. Matsuki et al., "Power transmission of a desk with a cord-free power supply," IEEE Transactions on Magnetics, vol. 38, no. 5 I, pp. 3329-3331, 2002.

[36] T. C. Beh, M. Kato, T. Imura, S. Oh, and Y. Hori, "Automated impedance matching system for robust wireless power transfer via magnetic resonance coupling," IEEE Transactions on Industrial Electronics, vol. 60, no. 9, pp. 3689-3698, 2013.

[37] T.-W. Yoo and K. Chang, "Theoretical and experimental development of 10 and $35 \mathrm{GHz}$ rectennas," IEEE Transactions on Microwave Theory and Techniques, vol. 40, no. 6, pp. 1259-1266, 1992.

[38] J. A. Hagerty, F. B. Helmbrecht, W. H. McCalpin, R. Zane, and Z. B. Popović, "Recycling ambient microwave energy with broadband rectenna arrays," IEEE Transactions on Microwave Theory and Techniques, vol. 52, no. 3, pp. 1014-1024, 2004.

[39] E. Waffenschmidt and T. Staring, "Limitation of inductive power transfer for consumer applications," in Proceedings of the 13th European Conference on Power Electronics and Applications (EPE '09), Barcelona, Spain, September 2009.

[40] W. X. Zhong, C. K. Lee, and S. Y. Hui, "Wireless power dominoresonator systems with noncoaxial axes and circular structures," IEEE Transactions on Power Electronics, vol. 27, no. 11, pp. 47504762, 2012.

[41] M. Dionigi, A. Costanzo, and M. Mongiardo, "Network methods for analysis and design of resonant wireless power transfer systems," in Wireless Power Transfer-Principles and Engineering Explorations, K. Y. Kim, Ed., InTech, 2012. 
[42] S. Atluri and M. Ghovanloo, "Design of a wideband powerefficient inductive wireless link for implantable biomedical devices using multiple carriers," in Proceedings of the 2nd International IEEE EMBS Conference on Neural Engineering, pp. 533-537, March 2005.

[43] R. J. Sedwick, "A fully analytic treatment of resonant inductive coupling in the far field," in Wireless Power Transfer-Principles and Engineering Explorations, K. Y. Kim, Ed., InTech, 2012.

[44] A. Kurs, A. Karalis, R. Moffatt, J. D. Joannopoulos, P. Fisher, and M. Soljačić, "Wireless power transfer via strongly coupled magnetic resonances," Science, vol. 317, no. 5834, pp. 83-86, 2007.

[45] A. Kurs, R. Moffatt, and M. Soljačić, "Simultaneous mid-range power transfer to multiple devices," Applied Physics Letters, vol. 96, no. 4, Article ID 044102, 2010.

[46] J. Kim, H.-C. Son, D.-H. Kim, and Y.-J. Park, "Optimal design of a wireless power transfer system with multiple self-resonators for an LED TV," IEEE Transactions on Consumer Electronics, vol. 58, no. 3, pp. 775-780, 2012.

[47] F. Zhang, X. Liu, S. A. Hackworth, R. J. Sclabassi, and M. Sun, "In vitro and in vivo studies on wireless powering of medical sensors and implantable devices," in Proceedings of IEEE/NIH Life Science Systems and Applications Workshop (LiSSA '09), pp. 84-87, April 2009.

[48] A. Kumar, S. Mirabbasi, and M. Chiao, "Resonance-based wireless power delivery for implantable devices," in Proceedings of IEEE Biomedical Circuits and Systems Conference (BioCAS '09), pp. 25-28, November 2009.

[49] T. Imura, T. Uchida, and Y. Hori, "Flexibility of contactless power transfer using magnetic resonance coupling to air gap and misalignment for EV,' World Electric Vehicle Journal, vol. 3, no. 1, pp. 24-34, 2009.

[50] P. Si, A. P. Hu, S. Malpas, and D. Budgett, "A frequency control method for regulating wireless power to implantable devices," IEEE Transactions on Biomedical Circuits and Systems, vol. 2, no. 1, pp. 22-29, 2008.

[51] H. Sugiyama, "Optimal designs for wireless resonant energy link based on nonradiative magnetic field," in Proceedings of 13 th IEEE International Symposium on Consumer Electronics (ISCE '09), pp. 428-429, May 2009.

[52] S. Cheon, Y.-H. Kim, S.-Y. Kang, M. L. Lee, J.-M. Lee, and T. Zyung, "Circuit-model-based analysis of a wireless energytransfer system via coupled magnetic resonances," IEEE Transactions on Industrial Electronics, vol. 58, no. 7, pp. 2906-2914, 2011.

[53] C. M. Zierhofer and E. S. Hochmair, "Geometric approach for coupling enhancement of magnetically coupled coils," IEEE Transactions on Biomedical Engineering, vol. 43, no. 7, pp. 708714, 1996.

[54] A. Karalis, J. D. Joannopoulos, and M. Soljačić, "Efficient wireless non-radiative mid-range energy transfer," Annals of Physics, vol. 323, no. 1, pp. 34-48, 2008.

[55] S. L. Ho, J. Wang, W. N. Fu, and M. Sun, "A comparative study between novel witricity and traditional inductive magnetic coupling in wireless charging," IEEE Transactions on Magnetics, vol. 47, no. 5, pp. 1522-1525, 2011.

[56] S.-H. Lee and R. D. Lorenz, "Development and validation of model for 95\%-efficiency 220 -W wireless power transfer over a 30-cm air gap," IEEE Transactions on Industry Applications, vol. 47, no. 6, pp. 2495-2504, 2011.

[57] H. Hirayama, "Equivalent circuit and calculation of its parameters of magnetic-coupled-resonant wireless power transfer," in Wireless Power Transfer-Principles and Engineering Explorations, K. Y. Kim, Ed., InTech, 2012.

[58] J. Wang, S. L. Ho, W. Fu, C. T. Kit, and M. Sun, "Finite-element analysis and corresponding experiments of resonant energy transfer for wireless transmission devices," IEEE Transactions on Magnetics, vol. 47, no. 5, pp. 1074-1077, 2011.

[59] R. E. Hamam, A. Karalis, J. D. Joannopoulos, and M. Soljačić, "Efficient weakly-radiative wireless energy transfer: an EIT-like approach," Annals of Physics, vol. 324, no. 8, pp. 1783-1795, 2009.

[60] F. Zhang, S. A. Hackworth, W. Fu, C. Li, Z. Mao, and M. Sun, "Relay effect of wireless power transfer using strongly coupled magnetic resonances," IEEE Transactions on Magnetics, vol. 47, no. 5, pp. 1478-1481, 2011.

[61] H. Hoang and F. Bien, "Maximizing efficiency of electromagnetic resonance wireless power transmission systems with adaptive circuits," in Wireless Power Transfer-Principles and Engineering Explorations, K. Y. Kim, Ed., InTech, 2012.

[62] W. Zhong, C. K. Lee, and S. Y. R. Hui, "General analysis on the use of Tesla's resonators in domino forms for wireless power transfer," IEEE Transactions on Industrial Electronics, vol. 60, no. 1, pp. 261-270, 2013.

[63] C. K. Lee, W. X. Zhong, and S. Y. R. Hui, "Effects of magnetic coupling of nonadjacent resonators on wireless power dominoresonator systems," IEEE Transactions on Power Electronics, vol. 27, no. 4, pp. 1905-1916, 2012.

[64] S. Cheon, Y. H. Kim, S. Y. Kang, M. L. Lee, and T. Zyung, "Wireless energy transfer system with multiple coils via coupled magnetic resonances," ETRI Journal, vol. 34, no. 4, pp. 527-535, 2012.

[65] R. Koma, S. Nakamura, S. Ajisaka, and H. Hashimoto, "Basic analysis of the circuit model using relay antenna in magnetic resonance coupling position sensing system," in Proceedings of IEEE/ASME International Conference on Advanced Intelligent Mechatronics (AIM '11), pp. 25-30, July 2011.

[66] M. K. Watfa, H. AlHassanieh, and S. Selman, "Multi-hop wireless energy transfer in WSNs," IEEE Communications Letters, vol. 15, no. 12, pp. 1275-1277, 2011.

[67] Z. N. Low, R. A. Chinga, R. Tseng, and J. Lin, "Design and test of a high-power high-efficiency loosely coupled planar wireless power transfer system," IEEE Transactions on Industrial Electronics, vol. 56, no. 5, pp. 1801-1812, 2009.

[68] T. Imura and Y. Hori, "Maximizing air gap and efficiency of magnetic resonant coupling for wireless power transfer using equivalent circuit and Neumann formula," IEEE Transactions on Industrial Electronics, vol. 58, no. 10, pp. 4746-4752, 2011.

[69] M. W. Baker and R. Sarpeshkar, "Feedback analysis and design of RF power links for low-power bionic systems," IEEE Transactions on Biomedical Circuits and Systems, vol. 1, no. 1, pp. 28-38, 2007.

[70] C. V. Jones, The Unified Theory of Electrical Machines, Butterworths, London, UK, 1967.

[71] M. G. Say, Alternating Current Machines, Pitman, New York, NY, USA, 4th edition, 1976.

[72] R. R. A. Syms, E. Shamonina, and L. Solymar, "Magnetoinductive waveguide devices," IEE Proceedings: Microwaves, Antennas and Propagation, vol. 153, no. 2, pp. 111-121, 2006.

[73] A. Bodrov and S.-K. Sul, "Analysis of wireless power transfer by coupled mode theory (CMT) and practical considerations to increase power transfer efficiency," in Wireless Power TransferPrinciples and Engineering Explorations, K. Y. Kim, Ed., InTech, 2012. 
[74] G. Gonzalez, Microwave Transistor Amplifiers: Analysis and Design, Prentice-Hall, Upper Saddle River, NJ, USA, 2nd edition, 1996.

[75] D. M. Pozar, Microwave Engineering, Addison-Wesley, Reading, Mass, USA, 1990.

[76] J. H. Harlow, Electric Power Transformer Engineering, CRC Press, 2007.

[77] A. C. Franklin, D. P. Franklin, and S. A. Stigant, The J \& P Transformer Book: A Practical Technology of the Power Transformer, Butterworths, 1983.

[78] J. Avila-Rosales, Modeling of the Power Transformer for Electromagnetic Transient Studies in Power Systems, vol. 1, University of Wisconsin-Madison, 1980.

[79] M. Erol-Kantarci and H. T. Mouftah, "Suresense: sustainable wireless rechargeable sensor networks for the smart grid," IEEE Wireless Communications, vol. 19, no. 3, pp. 30-36, 2012.

[80] F. Li, W. Qiao, H. Sun et al., "Smart transmission grid: vision and framework," IEEE Transactions on Smart Grid, vol. 1, no. 2, pp. 168-177, 2010.

[81] L. L. Grigsby, Electric Power Generation, Transmission, and Distribution, CRC Press, 2012.

[82] M. Chetty and R. Buyya, "Weaving computational grids: how analogous are they with electrical grids?" Computing in Science and Engineering, vol. 4, no. 4, p. 61, 2002.

[83] W. Kempton and J. Tomić, "Vehicle-to-grid power implementation: from stabilizing the grid to supporting large-scale renewable energy," Journal of Power Sources, vol. 144, no. 1, pp. 280-294, 2005.

[84] T. Flick and J. Morehouse, Securing the Smart Grid: Next Generation Power Grid Security, Syngress, 2010.

[85] A. Keyhani, Design of Smart Power Grid Renewable Energy Systems, Wiley-IEEE Press, 2011.

[86] U.S. Department of Energy, "Large Power Transformers and the U.S. Electric Grid," Tech. Rep., Infrastructure Security and Energy Restoration, Office of Electricity Delivery and Energy Reliability, June 2012, http://energy.gov/sites/prod/files/Large \%20Power\%20Transformer\%20Study\%20-\%20June\%202012_ $0 . p d f$.

[87] L. Xie, Y. Shi, Y. T. Hou, and H. D. Sherali, "Making sensor networks immortal: an energy-renewal approach with wireless power transfer," IEEE/ACM Transactions on Networking, vol. 20, no. 6, pp. 1748-1761, 2012.

[88] N. Shinohara, "Power without wires," IEEE Microwave Magazine, vol. 12, no. 7, pp. S64-S73, 2011.

[89] F. Zhang, S. A. Hackworth, W. Fu, and M. Sun, "The relay effect on wireless power transfer using witricity," in Proceedings of the 14th Biennial IEEE Conference on Electromagnetic Field Computation (CEFC '10), Chicago, Ill, USA, May 2010.

[90] R. R. A. Syms, E. Shamonina, V. Kalinin, and L. Solymar, "A theory of metamaterials based on periodically loaded transmission lines: interaction between magnetoinductive and electromagnetic waves," Journal of Applied Physics, vol. 97, no. 6, Article ID 064909, 2005.

[91] R. R. A. Syms, L. Solymar, I. R. Young, and T. Floume, "Thinfilm magneto-inductive cables," Journal of Physics D, vol. 43, no. 5, Article ID 055102, 2010.

[92] E. M. Thomas, J. D. Heebl, C. Pfeiffer, and A. Grbic, "A power link study of wireless non-radiative power transfer systems using resonant shielded loops," IEEE Transactions on Circuits and Systems I, vol. 59, no. 9, pp. 2125-2136, 2012.
[93] G. Grandi, M. K. Kazimierczuk, A. Massarini, and U. Reggiani, "Stray capacitances of single-layer solenoid air-core inductors," IEEE Transactions on Industry Applications, vol. 35, no. 5, pp. 1162-1168, 1999.

[94] A. Massarini, M. K. Kazimierczuk, and G. Grandi, "Lumped parameter models for single- and multiple-layer inductors," in Proceedings of the 27th Annual IEEE Power Electronics Specialists Conference (PESC '96), pp. 295-301, January 1996.

[95] M. Bartoli, N. Noferi, A. Reatti, and M. K. Kazimierczuk, "Modeling Litz-wire winding losses in high-frequency power inductors," in Proceedings of the 27th Annual IEEE Power Electronics Specialists Conference (PESC '96), pp. 1690-1696, January 1996.

[96] Z. Yang, W. Liu, and E. Basham, "Inductor modeling in wireless links for implantable electronics," IEEE Transactions on Magnetics, vol. 43, no. 10, pp. 3851-3860, 2007.

[97] New EnglandWire Technologies, "LitzWire-Product N. E. W. Technologies," 2005, http://newenglandwire.com/.

[98] F. Tourkhani and P. Viarouge, "Accurate analytical model of winding losses in round Litz wire windings," IEEE Transactions on Magnetics, vol. 37, no. 1, pp. 538-543, 2001.

[99] Q. Yu and T. W. Holmes, "A study on stray capacitance modeling of inductors by using the finite element method," IEEE Transactions on Electromagnetic Compatibility, vol. 43, no. 1, pp. 88-93, 2001.

[100] G. S. Dimitrakakis, E. C. Tatakis, and E. J. Rikos, "A new model for the determination of copper losses in transformer windings with arbitrary conductor distribution under high frequency sinusoidal excitation," in Proceedings of the European Conference on Power Electronics and Applications (EPE '07), pp. 1-10, September 2007.

[101] C. D. Sijoy and S. Chaturvedi, "Calculation of accurate resistance and inductance for complex magnetic coils using the finite-difference time-domain technique for electromagnetics," IEEE Transactions on Plasma Science, vol. 36, no. 1, pp. 70-79, 2008.

[102] G. Grandi, M. K. Kazimierczuk, A. Massarini, and U. Reggiani, "Stray capacitances of single-layer air-core inductors for highfrequency applications," in Proceedings of the 31st IAS Annual Meeting on Industry Applications Conference, pp. 1384-1388, October 1996.

[103] B. L. Cannon, J. F. Hoburg, D. D. Stancil, and S. C. Goldstein, "Magnetic resonant coupling as a potential means for wireless power transfer to multiple small receivers," IEEE Transactions on Power Electronics, vol. 24, no. 7, pp. 1819-1825, 2009.

[104] J. C. Maxwell, A Treatise on Electricity and Magnetism, Dover, New York, NY, USA, 1954.

[105] IEEE-International Committee on Electromagnetic Safety ICES, "Standard for Safety Levels with Respect to Human Exposure to Radio Frequency Electromagnetic Fields, $3 \mathrm{kHz}$ to 300 GHz," IEEE Std. C95.1-1991, 1992.

[106] "Guidelines for limiting exposure to time-varying electric, magnetic, and electromagnetic fields (up to $300 \mathrm{GHz}$ )," Health Physics, vol. 74, no. 4, pp. 494-522, 1998.

[107] F. van der Pijl, P. Bauer, and M. Castilla, "Control method for wireless inductive energy transfer systems with relatively large air gap," IEEE Transactions on Industrial Electronics, vol. 60, no. 1, pp. 213-390, 2013.

[108] A. J. Moradewicz and M. P. Kazmierkowski, "Contactless energy transfer system with FPGA-controlled resonant converter," IEEE Transactions on Industrial Electronics, vol. 57, no. 9, pp. 3181-3190, 2010. 
[109] H. H. Wu, J. T. Boys, and G. A. Covic, "An AC processing pickup for IPT systems," IEEE Transactions on Power Electronics, vol. 25, no. 5, pp. 1275-1284, 2010.

[110] J. A. Dobrowolski, Microwave Network Design Using the Scattering Matrix, Artech House, Norwood, Mass, USA, 2010.

[111] R. Mavaddat, Network Scattering Parameters. Advanced Series in Circuits and Systems, World Scientific, River Edge, NJ, USA, 2nd edition, 1996.

[112] X. Liu and S. Y. R. Hui, "An analysis of a double-layer electromagnetic shield for a universal contactless battery charging platform," in Proceedings of the 36th IEEE Power Electronics Specialists Conference, pp. 1767-1772, June 2005.

[113] J. C. Lin, "Safety standards for human exposure to radio frequency radiation and their biological rationale," IEEE Microwave Magazine, vol. 4, no. 4, pp. 22-26, 2003.

[114] J. M. Fernandez and J. A. Borras, "Contactless battery charger with wireless control link," US patent number 6,184,651, issued in February 2001.

[115] G. Scheible, B. Smailus, M. Klaus, K. Garrels, and L. Heinemann, "System for wirelessly supplying a large number of actuators of a machine with electrical power," US patent number 6,597,076, July 2003.

[116] L. Ka-Lai, J. W. Hay, and P. G. W. Beart, "Contact-less power transfer," US patent number 7,042,196, May 2006.

[117] J. Wang, J. Li, S. L. Ho et al., "Lateral and angular misalignments analysis of a new PCB circular spiral resonant wireless charger," IEEE Transactions on Magnetics, vol. 48, no. 11, pp. 4522-4525, 2012.

[118] U.-M. Jow and M. Ghovanloo, "Design and optimization of printed spiral coils for efficient transcutaneous inductive power transmission," IEEE Transactions on Biomedical Circuits and Systems, vol. 1, no. 3, pp. 193-202, 2007.

[119] T. Komaru, M. Koizumi, K. Komurasaki, T. Shibata, and K. Kano, "Parametric evaluation of mid-range wireless power transmission," in Proceedings of the IEEE-ICIT International Conference on Industrial Technology (ICIT '10), pp. 789-792, March 2010.

[120] H. Hoang, S. Lee, Y. Kim, Y. Choi, and F. Bien, "An adaptive technique to improve wireless power transfer for consumer electronics," IEEE Transactions on Consumer Electronics, vol. 58, no. 2, pp. 327-332, 2012.

[121] H. Sugiyama, "Performance analysis of magnetic resonant system based on electrical circuit theory," in Wireless Power Transfer-Principles and Engineering Explorations, K. Y. Kim, Ed., InTech, 2012.

[122] J. Choi and C. Seo, "High-efficiency wireless energy transmission using magnetic resonance based on metamaterial with relative permeability equal to -1," Progress in Electromagnetics Research, vol. 106, pp. 33-47, 2010.

[123] B.-J. Jang, S. Lee, and H. Yoon, "HF-band wireless power transfer system: concept, issues, and design," Progress in Electromagnetics Research, vol. 124, pp. 211-231, 2012.

[124] V. Marian, B. Allard, C. Vollaire, and J. Verdier, "Strategy for microwave energy harvesting from ambient field or a feeding source," IEEE Transactions on Power Electronics, vol. 27, no. 11, pp. 4481-4491, 2012.

[125] E. Y. Chow, C.-L. Yang, Y. Ouyang, A. L. Chlebowski, P. P. Irazoqui, and W. J. Chappell, "Wireless powering and the study of RF propagation through ocular tissue for development of implantable sensors," IEEE Transactions on Antennas and Propagation, vol. 59, no. 6, pp. 2379-2387, 2011.
[126] L. Chen, S. Liu, Y. Zhou, and T. Cui, "An optimizable circuit structure for high-efficiency wireless power transfer," IEEE Transactions on Industrial Electronics, vol. 60, no. 1, pp. 339-349, 2013.

[127] C. Zhu, K. Liu, C. Yu, R. Ma, and H. Cheng, "Simulation and experimental analysis on wireless energy transfer based on magnetic resonances," in Proceedings of IEEE Vehicle Power and Propulsion Conference (VPPC '08), pp. 1-4, September 2008.

[128] Z. N. Low, J. J. Casanova, P. H. Maier, J. A. Taylor, R. A. Chinga, and J. Lin, "Method of load/fault detection for loosely coupled planar wireless power transfer system with power delivery tracking," IEEE Transactions on Industrial Electronics, vol. 57, no. 4, pp. 1478-1486, 2010.

[129] Y.-H. Kim, S.-Y. Kang, M.-L. Lee, B.-G. Yu, and T. Zyung, "Optimization of wireless power transmission through resonant coupling," in Proceedings of the 6th International ConferenceWorkshop on Compatability and Power Electronics (CPE '09), pp. 426-431, May 2009.

[130] L. Peng, J. Y. Wang, L. X. Ran, O. Breinbjerg, and N. A. Mortensen, "Performance analysis and experimental verification of mid-range wireless energy transfer through nonresonant magnetic coupling," Journal of Electromagnetic Waves and Applications, vol. 25, no. 5-6, pp. 845-855, 2011.

[131] H.-S. Kim, D.-H. Won, and B.-J. Jang, "Simple design method of wireless power transfer system using $13.56 \mathrm{MHz}$ loop antennas," in Proceedings of IEEE International Symposium on Industrial Electronics (ISIE '10), pp. 1058-1063, July 2010.

[132] W. H. Ko, S. P. Liang, and C. D. F. Fung, "Design of radiofrequency powered coils for implant instruments," Medical and Biological Engineering and Computing, vol. 15, no. 6, pp. 634640, 1977.

[133] M. Zargham and P. G. Gulak, "Maximum achievable efficiency in near-field coupled power-transfer systems," IEEE Transactions on Biomedical Circuits and Systems, vol. 6, no. 3, pp. 228245, 2012.

[134] R. R. Harrison, "Designing efficient inductive power links for implantable devices," in Proceedings of IEEE International Symposium on Circuits and Systems (ISCAS '07), pp. 2080-2083, May 2007.

[135] K. M. Silay, D. Dondi, L. Larcher et al., "Load optimization of an inductive power link for remote powering of biomedical implants," in Proceedings of IEEE International Symposium on Circuits and Systems (ISCAS '09), pp. 533-536, May 2009.

[136] G. Simard, M. Sawan, and D. Massicotte, "High-speed OQPSK and efficient power transfer through inductive link for biomedical implants," IEEE Transactions on Biomedical Circuits and Systems, vol. 4, no. 3, pp. 192-200, 2010.

[137] S. Ray, Electrical Power Systems: Concepts, Theory and Practice, Prentice-Hall of India, 2007.

[138] K.-H. Grote and E. K. Antonsson, Springer Handbook of Mechanical Engineering, vol. 10, Springer, 2009.

[139] J. Schlabbach and K.-H. Rofalski, Power System Engineering: Planning, Design, and Operation of Power Systems and Equipment, Wiley-VCH, 2008.

[140] E. Lakervi and E. J. Holmes, Electricity Distribution Network Design, vol. 21, Peter Peregrinus, 1995.

[141] M. V. Bakshi and U. A. Bakshi, Elements of Power Systems, Technical Publications, 2009.

[142] A. G. Lazaropoulos, “Towards modal integration of overhead and underground low-voltage and medium-voltage power line communication channels in the smart grid landscape: model 
expansion, broadband signal transmission characteristics, and statistical performance metrics (invited paper)," ISRN Signal Processing, vol. 2012, Article ID 121628, 17 pages, 2012.

[143] A. G. Lazaropoulos, "Review and progress towards the common broadband management of high-voltage transmission grids: model expansion and comparative modal analysis," ISRN Electronics, vol. 2012, Article ID 935286, 18 pages, 2012.

[144] S. Sivanagaraju, Electric Power Transmission and Distribution, Pearson Education India, 2008.

[145] U. A. Bakshi and M. V. Bakshi, Generation, Transmission and Distribution, Technical Publications Pune, Pune, India, 2001.

[146] J. C. de Sosa, Analysis and Design of High-Voltage Transmission Lines, iUniverse Incorporated, Bloomington, Ind, USA, 2010.

[147] MAKSAN, "Product Catalog: Power and Distribution Transformers," Tech. Rep., 2012.

[148] M. C. K. Wiltshire, J. B. Pendry, I. R. Young, D. J. Larkman, D. J. Gilderdale, and J. V. Hajnal, "Microstructured magnetic materials for rf flux guides in magnetic resonance imaging," Science, vol. 291, no. 5505, pp. 849-851, 2001.

[149] D. Schneider, "Wireless power at a distance is still far away," IEEE Spectrum, vol. 47, no. 5, pp. 34-39, 2010.

[150] D. J. Perreault, J. Hu, J. M. Rivasy et al., "Opportunities and challenges in very high frequency power conversion," in Proceedings of the 24th Annual IEEE Applied Power Electronics Conference and Exposition (APEC '09), pp. 1-14, February 2009.

[151] F. Blaabjerg, Z. Chen, and S. B. Kjaer, "Power electronics as efficient interface in dispersed power generation systems," IEEE Transactions on Power Electronics, vol. 19, no. 5, pp. 1184-1194, 2004.

[152] U. Reggiani, A. Massarini, L. Sandrolini et al., "Experimental verification of predicted electromagnetic fields radiated by straight interconnect cables carrying high-frequency current," in Power Tech Conference Proceedings, vol. 1, p. 5, Bologna, Italy, June 2003. 


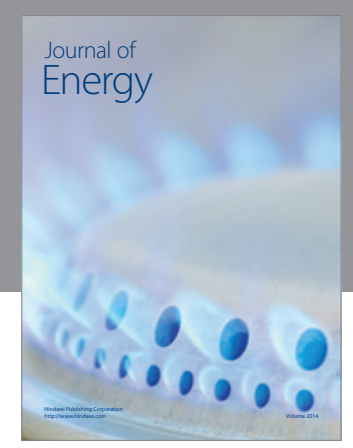

Journal of

Industrial Engineering
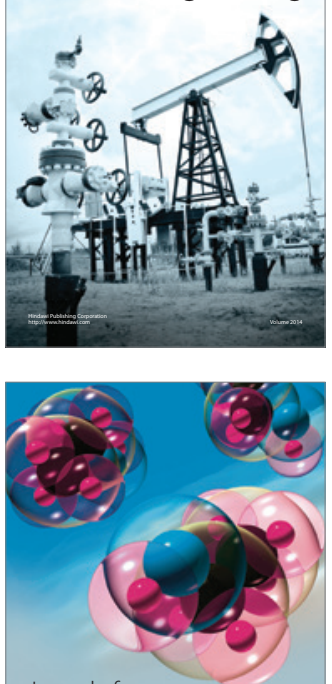

Fuels
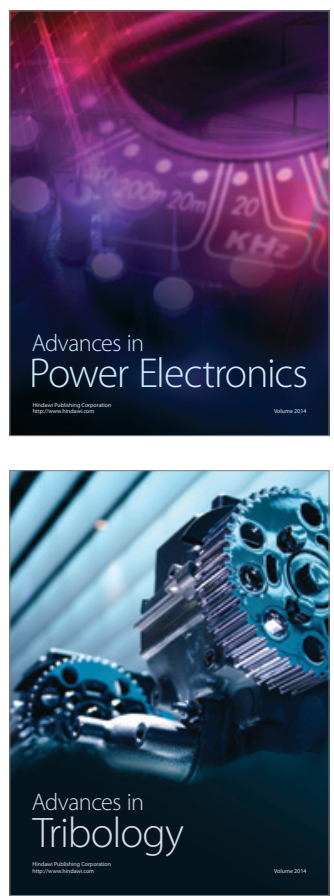

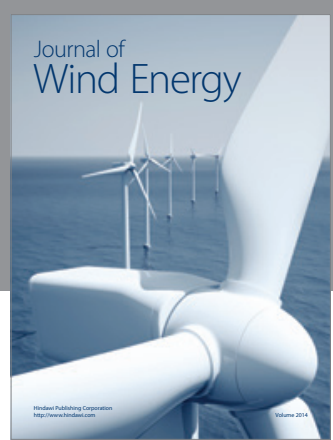

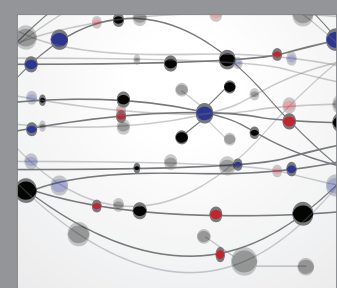

The Scientific World Journal

Submit your manuscripts at http://www.hindawi.com

Journal of

Structures
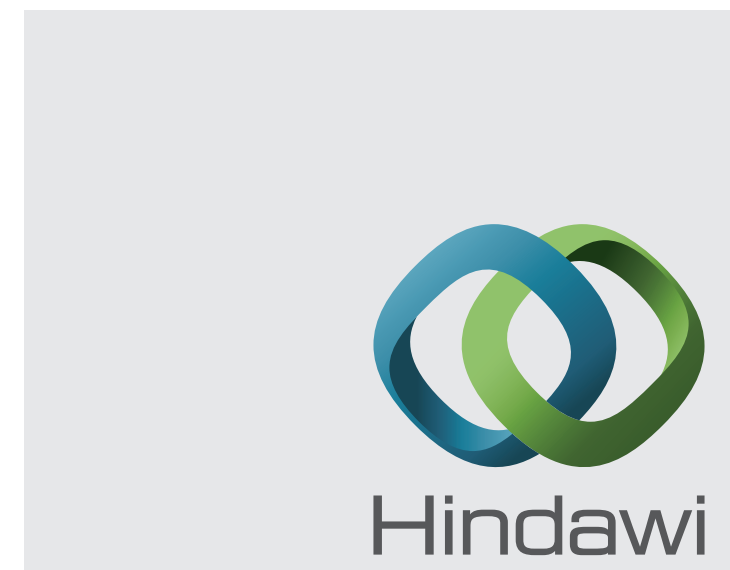

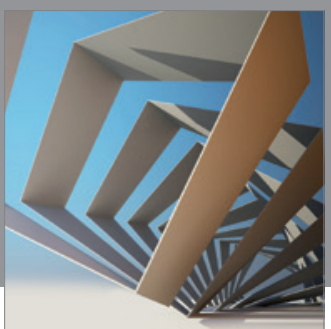

Rotating

Machinery
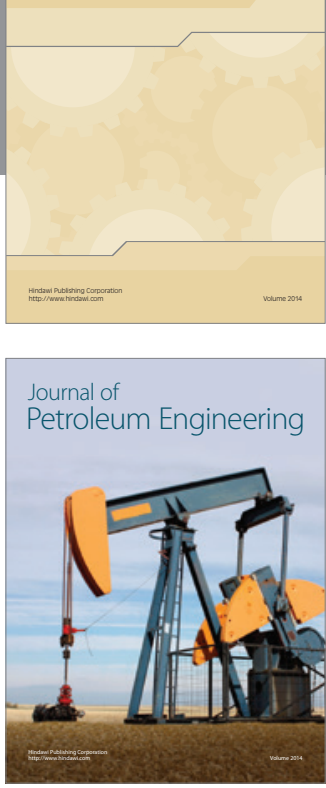

Journal of

Solar Energy
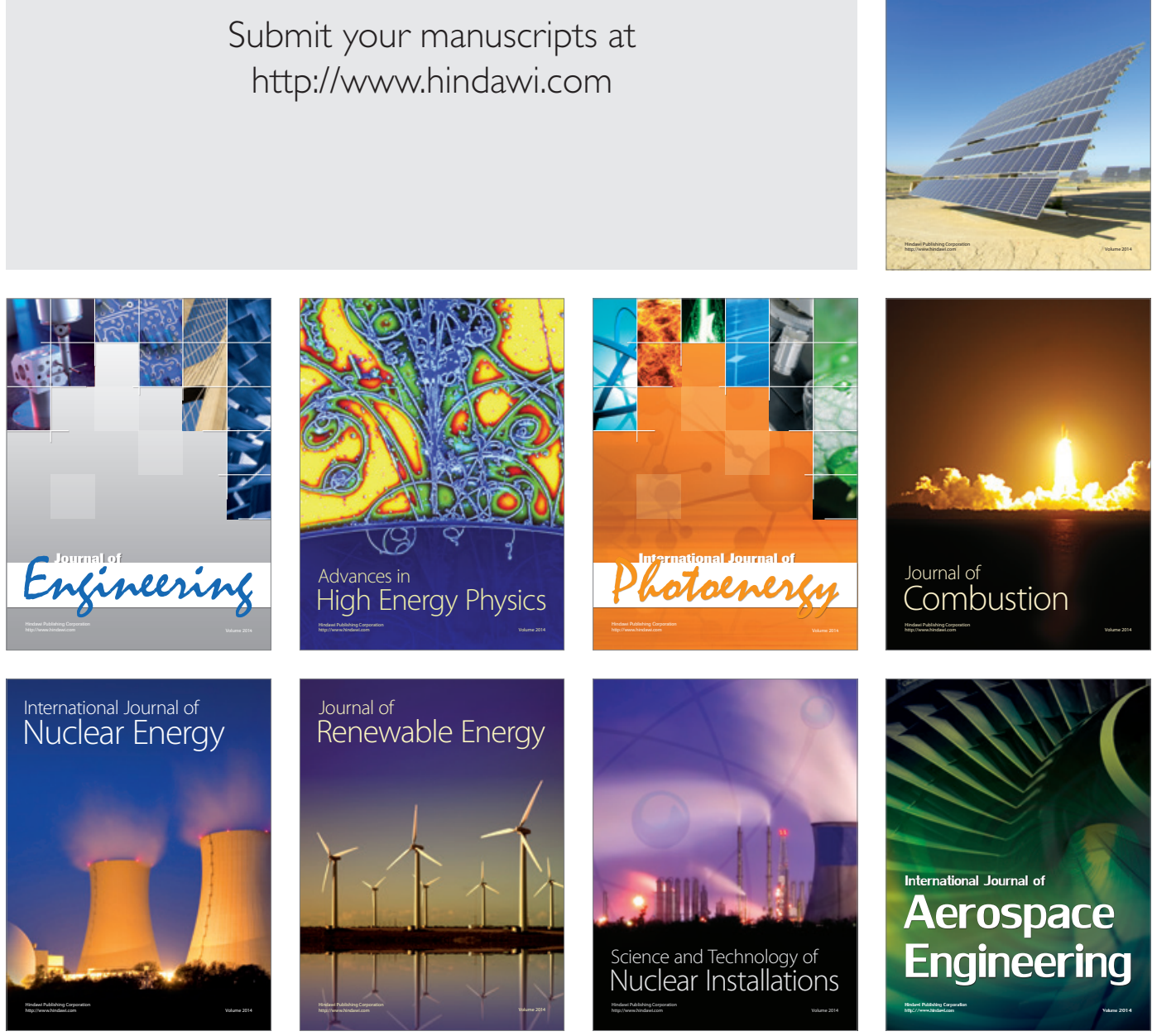